\title{
A decade of acoustic thermometry in the North Pacific Ocean
}

\author{
B. D. Dushaw, ${ }^{1}$ P. F. Worcester, ${ }^{2}$ W. H. Munk ${ }^{2}$ R. C. Spindel, ${ }^{1}$ J. A. Mercer, ${ }^{1}$ \\ B. M. Howe, ${ }^{1}$ K. Metzger Jr., ${ }^{3}$ T. G. Birdsall, ${ }^{3}$ R. K. Andrew, ${ }^{1}$ M. A. Dzieciuch, ${ }^{2}$ \\ B. D. Cornuelle, ${ }^{2}$ and D. Menemenlis ${ }^{4}$
}

Received 12 September 2008; revised 2 March 2009; accepted 8 April 2009; published 18 July 2009.

[1] Over the decade 1996-2006, acoustic sources located off central California (19961999) and north of Kauai (1997-1999, 2002-2006) transmitted to receivers distributed throughout the northeast and north central Pacific. The acoustic travel times are inherently spatially integrating, which suppresses mesoscale variability and provides a precise measure of ray-averaged temperature. Daily average travel times at 4-day intervals provide excellent temporal resolution of the large-scale thermal field. The interannual, seasonal, and shorter-period variability is large, with substantial changes sometimes occurring in only a few weeks. Linear trends estimated over the decade are small compared to the interannual variability and inconsistent from path to path, with some acoustic paths warming slightly and others cooling slightly. The measured travel times are compared with travel times derived from four independent estimates of the North Pacific: (1) climatology, as represented by the World Ocean Atlas 2005 (WOA05); (2) objective analysis of the upper-ocean temperature field derived from satellite altimetry and in situ profiles; (3) an analysis provided by the Estimating the Circulation and Climate of the Ocean project, as implemented at the Jet Propulsion Laboratory (JPL-ECCO); and (4) simulation results from a high-resolution configuration of the Parallel Ocean Program (POP) model. The acoustic data show that WOA05 is a better estimate of the time mean hydrography than either the JPL-ECCO or the POP estimates, both of which proved incapable of

reproducing the observed acoustic arrival patterns. The comparisons of time series provide a stringent test of the large-scale temperature variability in the models. The differences are sometimes substantial, indicating that acoustic thermometry data can provide significant additional constraints for numerical ocean models.

Citation: Dushaw, B. D., et al. (2009), A decade of acoustic thermometry in the North Pacific Ocean, J. Geophys. Res., 114, C07021, doi:10.1029/2008JC005124.

\section{Introduction}

[2] Long-range acoustic transmissions have now been used for over a quarter of a century to measure large-scale ocean temperature and heat content [Munk et al., 1995; Dushaw et al., 2001; Munk, 2006]. The acoustic transmissions in the first three-dimensional test of ocean acoustic tomography in 1981 [Ocean Tomography Group, 1982] were also recorded on bottom-mounted receivers at ranges of 1000-2000 km [Spiesberger et al., 1983]. One transmission path crossed the Gulf Stream, and travel time changes

\footnotetext{
${ }^{1}$ Applied Physics Laboratory, University of Washington, Seattle, Washington, USA.

${ }^{2}$ Scripps Institution of Oceanography, University of California at San Diego, La Jolla, California, USA.

${ }^{3}$ Department of Electrical Engineering and Computer Science, University of Michigan, Ann Arbor, Michigan, USA.

${ }^{4}$ Jet Propulsion Laboratory, California Institute of Technology, Pasadena, California, USA.

Copyright 2009 by the American Geophysical Union. 0148-0227/09/2008JC005124
}

primarily responded to north-south meandering of the front associated with this strong western boundary current. Travel times on another acoustic path that was entirely in the Sargasso Sea responded to the warming of the seasonal thermocline from spring to summer. These early measurements demonstrated the ability of acoustic transmissions to rapidly and repeatedly make range- and depth-averaged temperature measurements on gyre scales, taking advantage of the integrating nature of acoustic transmissions.

[3] Soon thereafter, measurements of basin-scale heat content in the northeast Pacific Ocean were made using a broadband $133-\mathrm{Hz}$ source mounted on the bottom at $183 \mathrm{~m}$ depth near Kaneohe, Hawaii, to transmit to bottom-mounted receivers 2000 to $4000 \mathrm{~km}$ distant [Spiesberger et al., 1989, 1992, 1998; Spiesberger and Tappert, 1996]. Measurements were made for 1 week in late 1983 and over two 5-month intervals between 1987 and 1989. During this same period, transmissions between three broadband $250-\mathrm{Hz}$ acoustic transceivers moored in a triangle approximately $1000 \mathrm{~km}$ on a side were used to determine the evolution of the largescale heat content in the central North Pacific from mid- 
May to mid-September 1987 [Dushaw et al., 1993b]. The $250-\mathrm{Hz}$ transmissions were also recorded on bottommounted receivers at longer ranges [Spiesberger and Metzger, 1991; Spiesberger et al., 1994; Norris et al., 1998].

\subsection{Heard Island Feasibility Test}

[4] In 1991, the Heard Island Feasibility Test (HIFT) was conducted to determine whether or not global-scale acoustic transmissions could be used to measure ocean warming [Munk et al., 1994]. An acoustic source near Heard Island in the southern Indian Ocean transmitted to receivers in the Atlantic, Pacific, and Indian Oceans. HIFT demonstrated that transmissions from controlled acoustic sources can be detected halfway around the world, at ranges of up to $20,000 \mathrm{~km}$. The observed arrival patterns were too complex and variable to permit ray identification and precise determination of travel times, however [McDonald et al., 1994]. The difficulty was likely due in part to the fact that only a small number of transmissions were made before poor weather terminated the experiment, making it difficult to recognize stable arrivals. In any event, from a climate point of view, the global-scale ranges in HIFT were not optimal, because they average across distinct climatic provinces, which respond differently to climate change [Munk et al., 1994]. The emphasis subsequently returned to more regional measurements, on gyre and basin scales.

\subsection{The Arctic Ocean and Mediterranean Sea}

[5] In the Arctic Ocean, the 1994 Transarctic Acoustic Propagation (TAP) experiment and the 1998-1999 Arctic Climate Observations using Underwater Sound (ACOUS) project detected substantial warming of the Arctic Intermediate Water using low-frequency transmissions centered at about $20 \mathrm{~Hz}$ [Mikhalevsky et al., 1999; Mikhalevsky and Gavrilov, 2001; Gavrilov and Mikhalevsky, 2006]. Temperature measurements made from both icebreakers and submarines subsequently confirmed the warming first observed in the acoustic measurements.

[6] Also in 1994, seven tomographic instruments were deployed across the Mediterranean Sea for 9 months in the THETIS-2 experiment, giving cross-basin transmissions from Europe to Africa [Send et al., 1997; Menemenlis et al., 1997; Skarsoulis et al., 2004]. These measurements demonstrated that acoustic methods could provide precise measurements of heat content across an entire, albeit small, ocean basin. These data were also used to demonstrate that basin-scale circulation could be derived from combined tomographic and altimetric data, with the aid of state-ofthe-art numerical models, as had been suggested much earlier by Munk and Wunsch [1982].

\subsection{The Pacific Ocean}

[7] Not long after HIFT, the Acoustic Thermometry of Ocean Climate (ATOC) program was started with the goal of making long-term measurements of gyre-scale temperatures and heat content in the northeast and north central Pacific Ocean. Acoustic sources were installed off central California and north of Kauai. The sources transmitted broadband signals centered at $75 \mathrm{~Hz}$ to receivers distributed throughout the North Pacific from 1996 through 1999 [Howe et al., 1995; Baggeroer et al., 1998; Dushaw,
1999; Dushaw et al., 1999]. The Kauai transmissions resumed in early 2002 and continued for nearly five more years until late 2006 as part of the North Pacific Acoustic Laboratory (NPAL) project [Worcester and Spindel, 2005]. These measurements had propagation ranges from about $1500 \mathrm{~km}$ to about $5500 \mathrm{~km}$. The durations were long enough to begin to examine seasonal [e.g., Moisan and Niiler, 1998] and interannual variability [e.g., Mantua et al., 1997; Miller and Schneider, 2000; Bond et al., 2003], as well as to look for longer-term climate trends [Willis et al., 2004; Levitus et al., 2005; Gouretski and Koltermann, 2007; Carton and Santorelli, 2008; Domingues et al., 2008].

[8] Preliminary results from ATOC and NPAL were presented by Howe et al. [2004]. Worcester et al. [2005] reviewed the history. Here the measured travel times are compared with travel times derived from four independent estimates of the North Pacific: (1) climatology, as represented by the World Ocean Atlas 2005 (WOA05); (2) objective maps of the upper-ocean temperature field, derived from satellite altimetry and in situ profiles [Willis et al., 2003, 2004, 2007; Lyman et al., 2006]; (3) a near-realtime analysis provided by the Estimating the Circulation and Climate of the Ocean project, as implemented at the Jet Propulsion Laboratory (JPL-ECCO) [Menemenlis et al., 2005]; and (4) simulation results from a high-resolution configuration of the Parallel Ocean Program (POP) [Maltrud and McClean, 2005]. Modern ocean general circulation models have the vertical resolution needed for acoustic propagation calculations, allowing straightforward comparison of measured and predicted travel times. The comparisons provide stringent tests of the accuracy of the mean states and large-scale, low-frequency variability in the models. The next step, which is not done here, is to use the acoustic data, together with altimetric and in situ profile data, to constrain the models.

[9] In section 2, the acoustic instrumentation and signal processing are described, and the measured travel times are compared with travel times computed using WOA05. In addition, travel time variability on seasonal and interannual time scales, as well as secular trends in the data (or lack thereof), are discussed. In section 3, the sampling properties of the acoustic travel time data are described. In section 4, the observed travel times are compared with travel times calculated using temperature profiles in the upper $750 \mathrm{~m}$ derived from a combination of altimetric and in situ profile data. Sections 5 and 6 make similar comparisons to travel times derived from the JPL-ECCO solution and the POP model, respectively. Finally, section 7 summarizes the results.

\section{Observed and Calculated Acoustic Travel Times: Climatology, Short-Period Fluctuations, and Secular Trends}

\subsection{Acoustic Instrumentation and Signal Processing}

[10] Two acoustic sources were installed for the ATOC project: Pioneer Seamount, $88 \mathrm{~km}$ west of Pillar Point, California, at a depth of $939 \mathrm{~m}$, and Kauai, on the seafloor $14.8 \mathrm{~km}$ north of Haena Point, at a depth of $811 \mathrm{~m}$ (Figure 1 and Table 1). They were mounted in tripods and connected by undersea cables to source control electronics and power amplifiers on shore. The sources were placed near the depth 


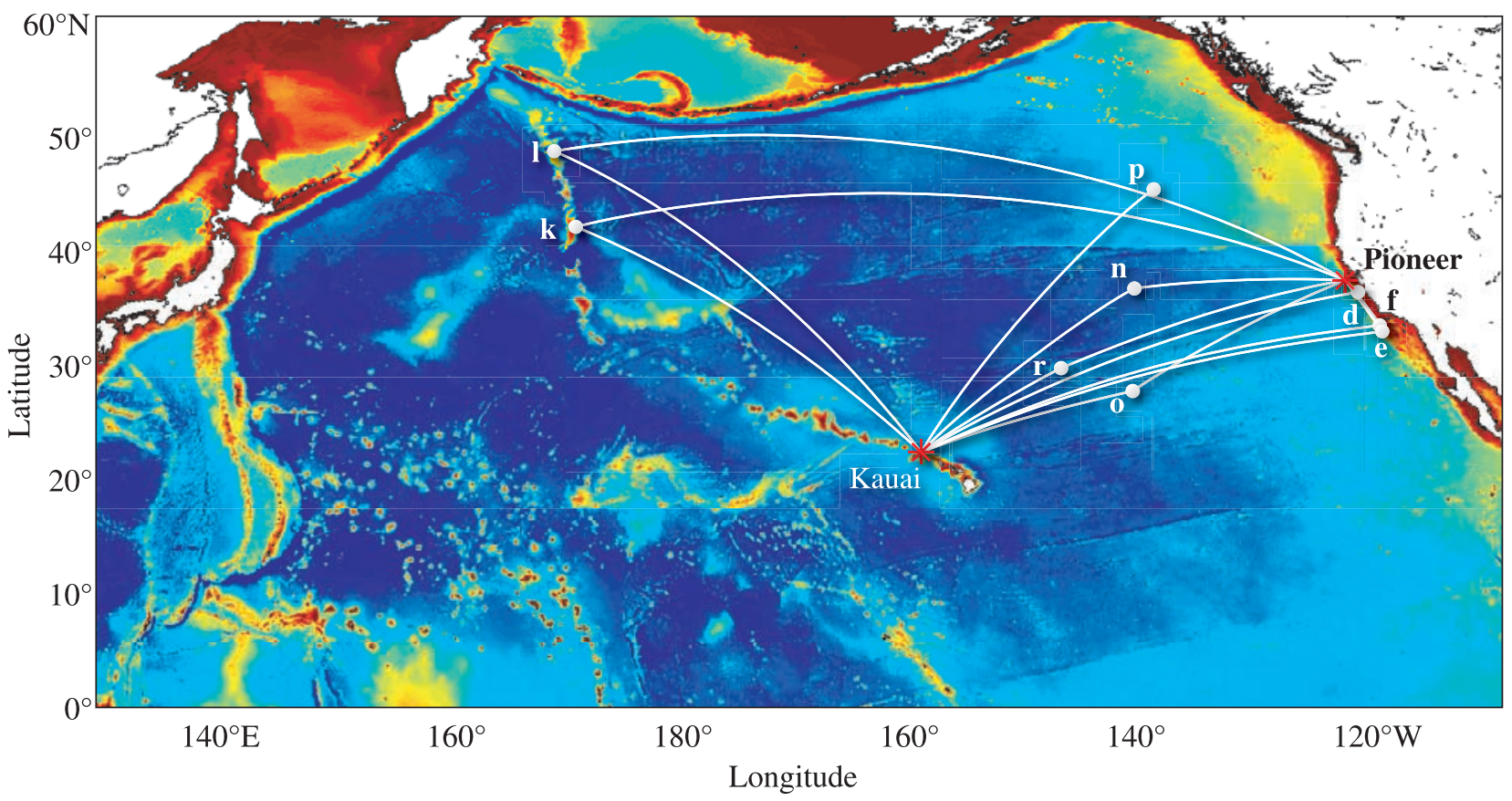

Figure 1. The acoustic thermometry array in the North Pacific Ocean superimposed on the bathymetry. Acoustic sources were located on Pioneer Seamount off central California and on the seafloor north of Kauai. The bottom-mounted hydrophone arrays used here are indicated by letters.

of the sound channel axis in locations with unobstructed views out into the deep ocean. The sources transmitted phase-modulated broadband signals centered at $75 \mathrm{~Hz}$.

[11] Transmissions from the acoustic source on Pioneer Seamount at the maximum authorized source level of $195 \mathrm{~dB}$ re $1 \mu \mathrm{Pa}$ at $1 \mathrm{~m}(263 \mathrm{~W})$ began on 28 December 1995 and continued until 10 December 1998. Transmissions from the Kauai source began on 30 October 1997 and continued until 2 October 1999 as part of the ATOC project. After a hiatus while the necessary authorizations were obtained [Office of Naval Research, 2001], transmissions from the Kauai source resumed on 25 January 2002 as one component of the NPAL project. The transmissions continued until 17 September 2006, when they were terminated in accord with the relevant authorizations. After 9 years of operation the source itself was still functioning properly.
[12] The sources typically transmitted every fourth day (i.e., 91 days per year). On transmission days, there were six transmissions at 4-h intervals. The overall duty cycle was typically two percent. During ATOC, the transmissions were under the control of the ATOC Marine Mammal Research Program [Advanced Research Projects Agency (ARPA) and National Marine Fisheries Service, 1995; ARPA et al., 1995], and the schedules were modified in accord with marine mammal research protocols. The transmissions were therefore somewhat irregular, particularly for the Pioneer Seamount source, where aerial surveys of marine mammals were often constrained by weather conditions.

[13] The receivers included bottom-mounted horizontal hydrophone arrays connected to shore by undersea cables (Figure 1 and Table 1) and autonomous, moored vertical hydrophone arrays developed for the ATOC project. The

Table 1. Acoustic Source and Receiver Locations ${ }^{\mathrm{a}}$

\begin{tabular}{|c|c|c|c|c|c|}
\hline & \multirow[b]{2}{*}{ Latitude $\left({ }^{\circ} \mathrm{N}\right)$} & \multirow[b]{2}{*}{ Longitude $\left({ }^{\circ} \mathrm{E}\right)$} & \multirow[b]{2}{*}{ Depth (m) } & \multicolumn{2}{|c|}{ Range $(\mathrm{km})$} \\
\hline & & & & Pioneer & Kauai \\
\hline Pioneer & 37.342583 & -123.445195 & 939 & & \\
\hline Kauai & 22.349156 & -159.569924 & 811 & & \\
\hline d & 36.299133 & -122.393850 & 1359 & 149.019 & 3897.555 \\
\hline $\mathrm{f}$ & 33.376900 & -120.615219 & 1100 & & 3999.970 \\
\hline $\mathrm{k}$ & 42.007 & 170.982 & 1000 & 5511.005 & 3499.872 \\
\hline 1 & 48.596 & 169.186 & 1000 & 5451.515 & \\
\hline $\mathrm{n}$ & 36.432 & -141.532 & 2500 & 1613.006 & 2337.987 \\
\hline o & 27.587 & -141.612 & 2500 & 2016.103 & 1901.622 \\
\hline $\mathrm{p}$ & 44.883 & -139.894 & 2500 & 1610.965 & \\
\hline $\mathrm{r}$ & 29.583500 & -147.742920 & 1320 & & 1428.670 \\
\hline
\end{tabular}

${ }^{a}$ Precise positions are given for receivers $(\mathrm{d}, \mathrm{f}, \mathrm{r})$, while only notional positions can be provided for receivers $(\mathrm{k}, \mathrm{l}, \mathrm{n}, \mathrm{o}, \mathrm{p})$. All travel time calculations shown in this article were done for the locations given here. 


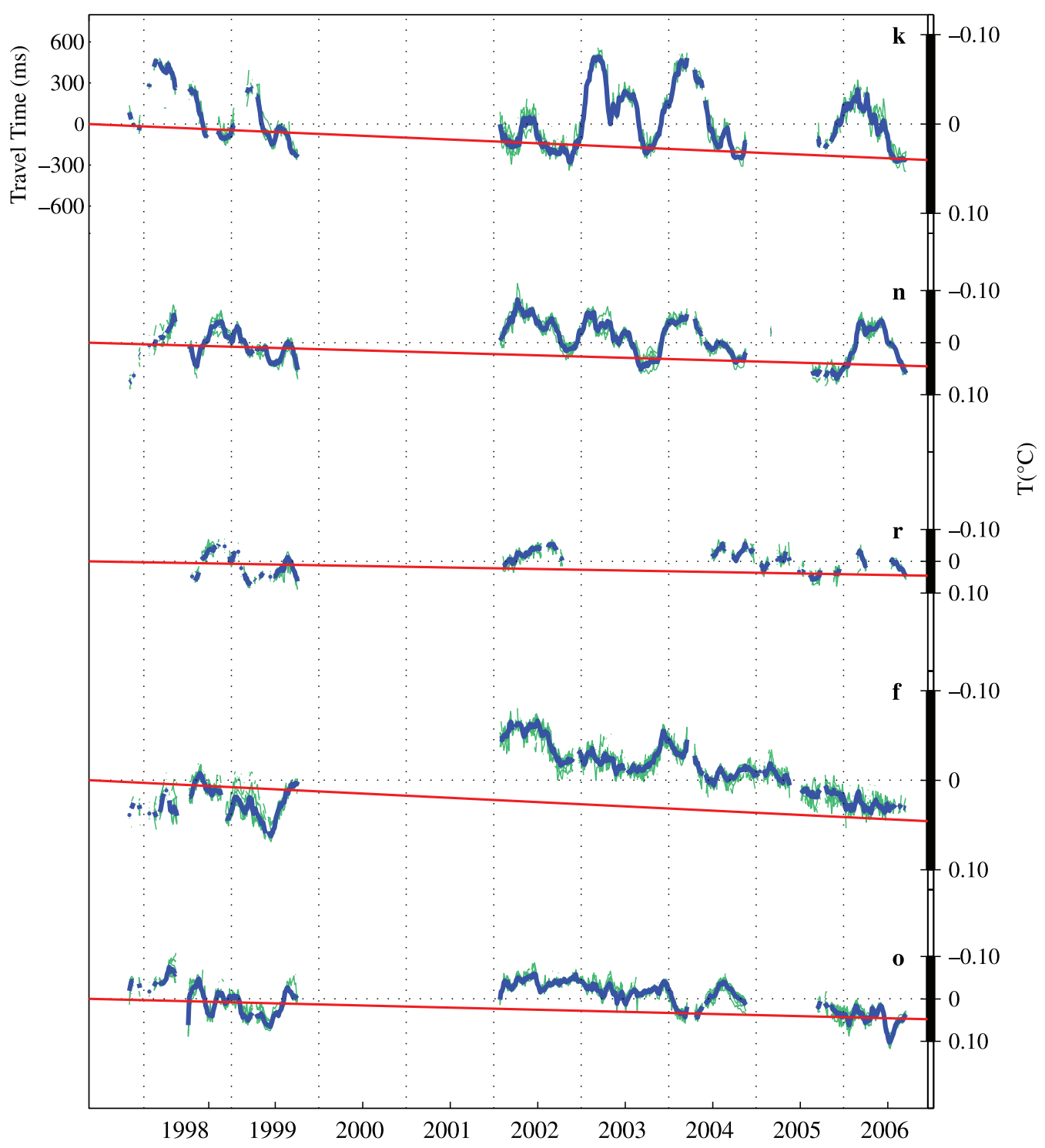

Figure 2. Acoustic travel times for transmissions from the acoustic source north of Kauai to various receivers distributed around the North Pacific, as indicated in Figure 1. The mean has been removed from each time series. The daily-average travel times for each of the resolved ray arrivals are plotted (thin green lines), together with combined daily-average travel times, in which the 5-12 daily-average travel times for each of the resolved ray arrivals were combined to produce a single daily-average travel time (thick blue lines). Approximate estimates of temperature perturbations averaged along the raypaths inferred from the travel times are shown on the right-hand axis. Positive temperature anomalies correspond to negative travel time anomalies, and the temperature axis is therefore reversed from the usual orientation. The time series are displayed roughly from north to south, with the most northern path at the top. The nominal travel time trends corresponding to a warming of $5 \mathrm{~m}^{\circ} \mathrm{C} / \mathrm{a}$ on the sound-channel axis, as suggested by Munk and Forbes [1989], are shown (red).

bottom-mounted arrays provided the long-duration time series presented in this article. The acoustic data from the bottom-mounted receivers for transmissions from the Pioneer Seamount source are described in detail by Dushaw et al. [1999]. The processing of the receptions from the Kauai source was identical to the processing described by Dushaw et al. [1999] for receptions from the Pioneer Seamount source.

[14] The moored vertical arrays were developed in order to improve our understanding of long-range acoustic prop- agation in deep water, especially the influences that smallerscale processes such as internal waves, density-compensated fine structure (spice), and mesoscale eddies have on the signals [Worcester et al., 1999]. The vertical arrays were deployed for periods of up to about 1 year, providing much shorter time series than the bottom-mounted receivers. The time series from the vertical arrays will not be discussed further here.

[15] The acoustic instrumentation and signal processing are described in more detail in Appendix A. 


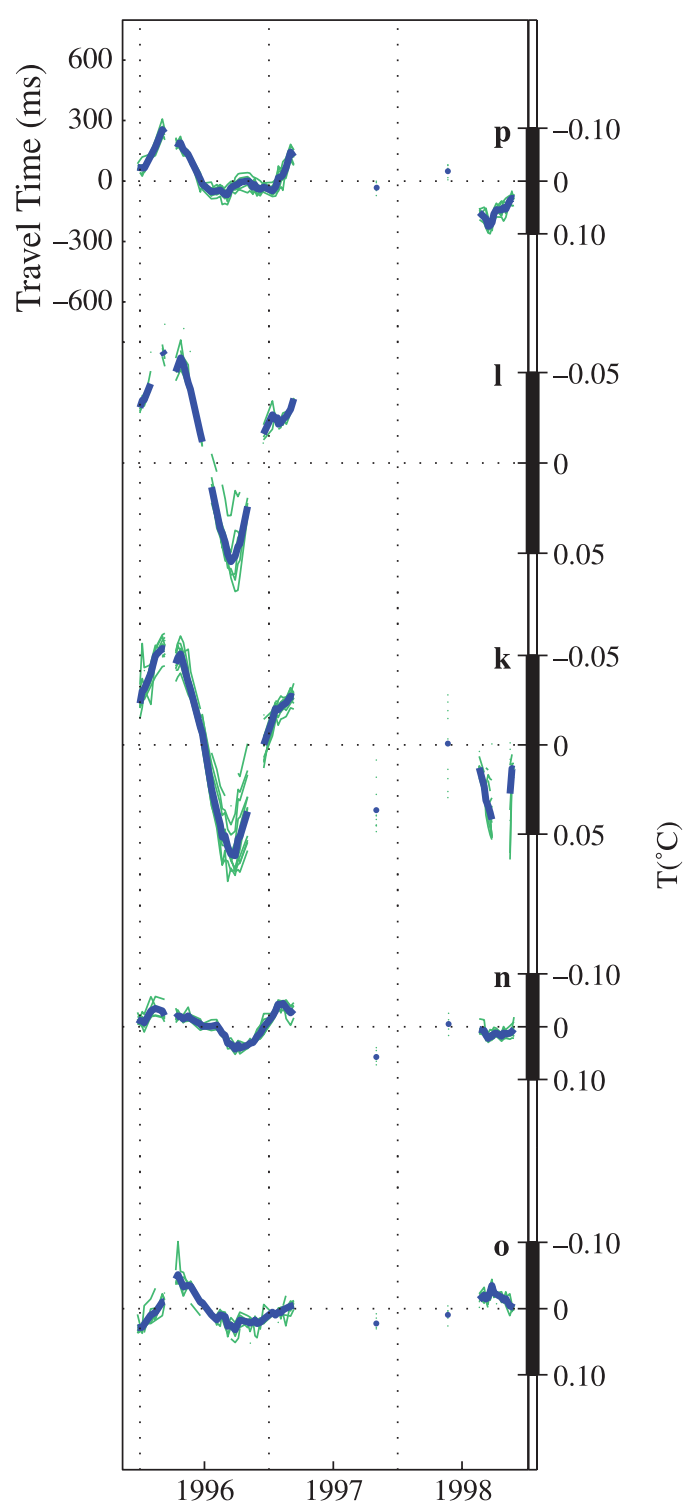

Figure 3. Same as Figure 2, except for transmissions from the acoustic source on Pioneer Seamount off central California.

\subsection{Travel Times and Climatology}

[16] Figures 2 and 3 summarize the time series of travel times for transmissions from the Kauai and Pioneer Seamount sources, respectively. From five to 12 stable arrivals corresponding to geometric rays are typically resolved in the receptions at each bottom-mounted receiver [Dushaw et al., 1999]. The plotted travel times are daily averages of (typically) six receptions. The daily averaging was done to reduce high-frequency fluctuations due to internal waveinduced scattering, barotropic and baroclinic tides, and ambient acoustic noise. Because of bottom interactions near the source and/or receiver, the acoustic arrival patterns are complex. The daily averaging also reduces the effects of errors made in constructing time series of travel times from such arrival patterns. No other time averaging has been done. The mean was removed from each time series before plotting, emphasizing the variability.

[17] The stable arrivals were identified with specific acoustic rays by comparing the measured arrival patterns to arrival patterns computed for sound speed fields derived from climatology, as represented by the WOA05 [Locarnini et al., 2006; Antonov et al., 2006] using the sound speed equation of Del Grosso [1974].

[18] In order to simplify comparison of the measured travel times with model predictions in subsequent sections, the five to 12 daily-average travel times for the resolved rays on each acoustic path were combined to produce a single daily-average travel time (Figures 2 and 3). Stable ray arrivals with high signal-to-noise ratios were given greater weight than weak arrivals in this average. The weighted RMS of the deviations of the five to 12 daily-average travel times on each acoustic path from the combined dailyaverage travel times is roughly $25 \mathrm{~ms}$ (Table 2 ). The small size of the deviations reflects the fact that the resolved ray arrivals on each path are high-angle rays that sample the ocean more or less similarly, as will be discussed in the next section. The somewhat larger RMS deviation for the Pioneer to $\mathrm{k}$ path occurs because the rays in this case actually do sample the ocean somewhat differently, particularly in late summer and early fall when the summer thermocline is fully developed (Figure 3). For an RMS deviation of $25 \mathrm{~ms}$ and six or more ray travel times in each average, the RMS uncertainty in the combined daily-average travel time is roughly $10 \mathrm{~ms}$. The time series of the combined dailyaverage travel times will be used in the remainder of this article.

[19] The monthly atlases available from WOA05 allow a comparison of the measured and climatological seasonal cycles for each acoustic path. Figures 4 and 5 show the time series of the average travel times for each path together with the travel times computed from WOA05. In this comparison, and in all subsequent comparisons, the computed ray travel times have the same identification as the measured travel times. (The travel times computed from the WOA05 monthly averages are simply replicated each year.) The measured and computed seasonal cycles are roughly comparable, although the monthly values from WOA05 of course show neither the variability in the seasonal cycle from year to year nor the interannual and longer-term variability evident in the measured travel times.

Table 2. Weighted RMS of the Deviations of the Daily-Average Travel Times From the Combined Daily-Average Travel Times

\begin{tabular}{lccc}
\hline Source & Receiver & Number of Rays & RMS (ms) \\
\hline Kauai & $\mathrm{k}$ & 6 & 30 \\
Kauai & $\mathrm{n}$ & 6 & 28 \\
Kauai & $\mathrm{r}$ & 6 & 21 \\
Kauai & $\mathrm{f}$ & 9 & 34 \\
Kauai & $\mathrm{o}$ & 8 & 24 \\
Pioneer & $\mathrm{p}$ & 8 & 23 \\
Pioneer & 1 & 6 & 46 \\
Pioneer & $\mathrm{k}$ & 6 & 64 \\
Pioneer & $\mathrm{n}$ & 8 & 21 \\
Pioneer & $\mathrm{o}$ & 6 & 24 \\
\hline
\end{tabular}




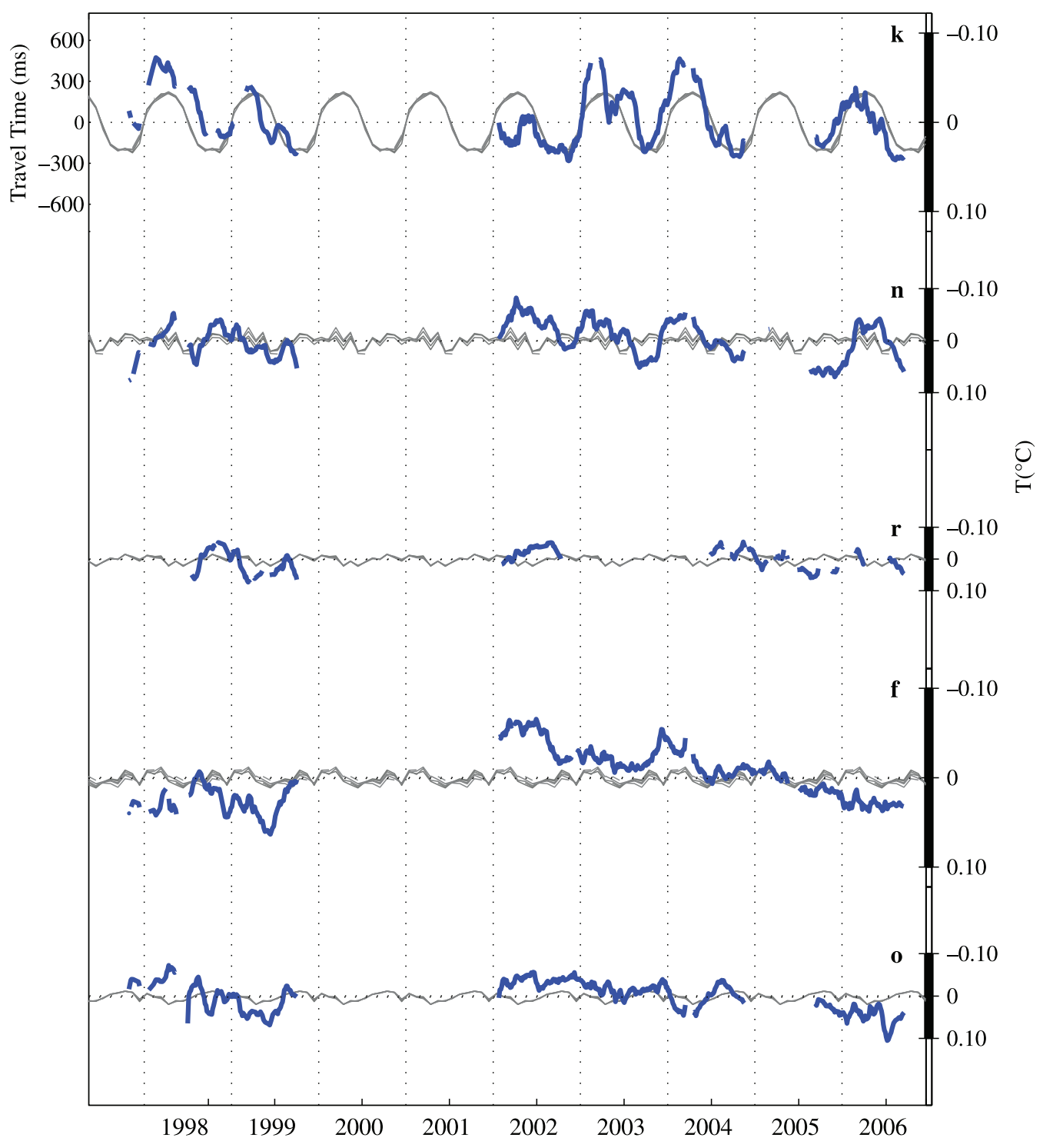

Figure 4. Comparison of measured travel times for transmissions from Kauai (blue) with travel times calculated using the World Ocean Atlas 2005 (WOA05) (gray). The time means have been removed from all of the time series. Approximate estimates of temperature perturbations averaged along the raypaths inferred from the travel times are shown on the right-hand axis. The results from WOA05 are repeated each year.

\subsection{Temperature, Salinity, and Sound Speed}

[20] Travel times provide a direct measure of sound speed perturbations averaged along the raypaths. For most oceanographic purposes, temperature and salinity are of more interest than sound speed. Although sound speed is a function of temperature, salinity, and pressure, temperature perturbations are normally by far the most important contributor to sound speed perturbations. Munk et al. [1995] and Worcester [2001] show that in midlatitudes sound speed perturbations caused by salinity perturbations are typically only a few percent of those caused by temperature perturbations, both because of the relatively weak dependence of sound speed on salinity and because of the typical magnitudes of temperature and salinity perturbations in the ocean. Somewhat larger salinity effects are on occasion possible, however. Repeated observations in the subtropical gyre near
Hawaii, for example, showed pronounced freshening ( $\sim 0.15 \mathrm{psu}$ ) and cooling $\left(\sim 0.5^{\circ} \mathrm{C}\right)$ of the upper thermocline from 1991 through 1997 [Lukas, 2001]. Even in this case, the sound speed perturbation due to the change in salinity is only about $10 \%$ of that due to the change in temperature.

[21] It is therefore appropriate to interpret travel time perturbations in terms of temperature perturbations averaged along the raypaths. Conversion from ray-average sound speed perturbations to ray-average temperature perturbations is not straightforward, however, because the derivative of temperature with respect to sound speed, $\partial T /$ $\partial C$ as determined from the equation for the speed of sound in seawater, varies significantly with temperature $[\mathrm{Del}$ Grosso, 1974; Dushaw et al., 1993a; Worcester, 2001]. Approximate estimates of the temperature perturbations averaged along the raypaths were generated assuming $\partial C /$ $\partial T=3.3 \mathrm{~m} / \mathrm{s}$ per ${ }^{\circ} \mathrm{C}$, corresponding to the value at about 


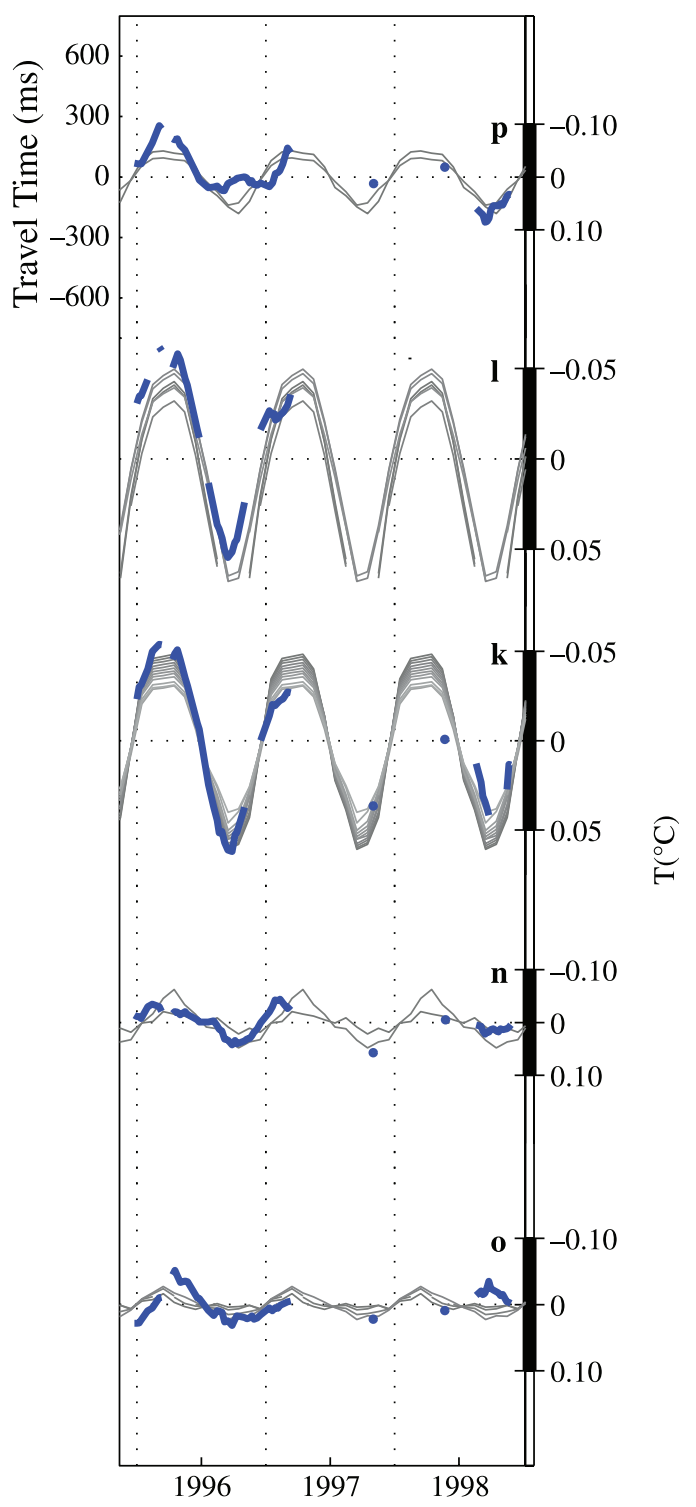

Figure 5. Same as Figure 4, except for transmissions from Pioneer Seamount.

$13^{\circ} \mathrm{C}$, to provide some feeling for the magnitudes of the rayaverage temperature perturbations corresponding to the measured travel time perturbations. These estimates are shown on the right-hand axes of all travel time plots in this article.

\subsection{Mesoscale-Induced Travel Time Fluctuations}

[22] Mesoscale variability is suppressed in the travel times [Semtner and Chervin, 1990; Chiu et al., 1994; Staten et al., 1996]. The travel time time series for Pioneer to $\mathrm{k}$ and 1 are particularly smooth (Figure 3 ), even though the only time averaging that has been done is the construction of daily averages. The travel time time series for the Kauai source contain more residual short-period variability, however (Figure 2). The origin of these differences can be understood by examining the geographic structure of the mesoscale variability in the North Pacific. In situ profiles from the Argo program (http://www.argo.net/) obtained between 2003 and the present were used to obtain a measure of the depth-integrated sound speed variability, which is relevant to interpreting the travel times. Sound speed profiles were first computed from the Argo data. Sound speed perturbations were then obtained by subtracting the WOA05 sound speed profile from each Argo profile. Finally, the perturbations were integrated between 150 and $1000 \mathrm{~m}$ depth and the RMS computed in $10^{\circ} \times 10^{\circ}$ squares (Figure 6). The integration was started at $150 \mathrm{~m}$ depth to minimize the effect of seasonal variability. The Pioneer to $\mathrm{k}$ and 1 paths are largely north of the Subarctic Front. The remarkably smooth nature of these time series is due in part to the low mesoscale energy levels in that region, which reach depth-averaged values as low as $0.5 \mathrm{~m} / \mathrm{s}$ and are all below $1.3 \mathrm{~m} / \mathrm{s}$. It is also due in part to the short Rossby radius north of the Subarctic Front, which means that the acoustic paths are averaging over many Rossby radii. The Kauai to $\mathrm{k}$ path, on the other hand, traverses regions of higher mesoscale variability, particularly around the Hawaiian Islands and in the Kuroshio Extension, resulting in more short-period variability in the travel times. The RMS depthaveraged fluctuation in the $10^{\circ} \times 10^{\circ}$ square in the Kuroshio Extension traversed by the Kauai to $\mathrm{k}$ path is $3.4 \mathrm{~m} / \mathrm{s}$.

[23] The travel time perturbations due to the mesoscale for the Pioneer to $\mathrm{k}$ and 1 paths can be roughly estimated from the RMS depth-averaged sound speed fluctuations on the path derived from Argo (approximately $0.6 \mathrm{~m} / \mathrm{s}$ ). The travel time perturbation $\Delta \tau$ due to a sound speed perturbation $\Delta C$ for a signal traveling a range $r$ along the sound channel axis is

$$
\Delta \tau=-\frac{\Delta C}{C^{2}} r
$$

The travel times depend on sound speed perturbations averaged over the depth range traversed by the ray (say $3000 \mathrm{~m}$ ), however, not over the top $1000 \mathrm{~m}$ as obtained from Argo data. Scaling the $0.6 \mathrm{~m} / \mathrm{s}$ RMS depth-averaged sound speed fluctuation in the top $1000 \mathrm{~m}$ to a $3000 \mathrm{~m}$ depth average, the effective sound speed perturbation along the ray is then roughly $0.2 \mathrm{~m} / \mathrm{s}$. If this $\Delta C$ were uniform over a range of $5.5 \mathrm{Mm}$, the corresponding $\Delta \tau$ would be about 0.5 s. A $5.5-\mathrm{Mm}$ path traverses about 220 mesoscale correlation lengths, assuming a $25 \mathrm{~km}$ length scale for mesoscale perturbations north of the Subarctic Front. The travel time perturbation due to mesoscale variability is then very roughly $0.5 \mathrm{~s} / \sqrt{220}=30 \mathrm{~ms}$ RMS. This estimate is roughly consistent with the short-term fluctuations with periods of a month or so seen in Figure 3.

[24] A similar calculation for the Kauai to $\mathrm{k}$ path, but using an RMS depth-averaged sound speed fluctuation of $1.5 \mathrm{~m} / \mathrm{s}$ RMS, a range of $4 \mathrm{Mm}$, and a mesoscale length scale of $50 \mathrm{~km}$, results in an estimate for the travel time perturbation due to mesoscale variability of very roughly $100 \mathrm{~ms}$ RMS. Again, this is not inconsistent with the shortterm variability seen in Figure 2. In this case, the $4-\mathrm{Mm}$ path traverses about 80 mesoscale correlation lengths.

\subsection{Secular Trends in Travel Time}

[25] One of the original goals of these measurements was to detect small secular changes in ocean temperatures as a result of global warming. Simulations performed in conjunction with HIFT using results from a global eddy- 


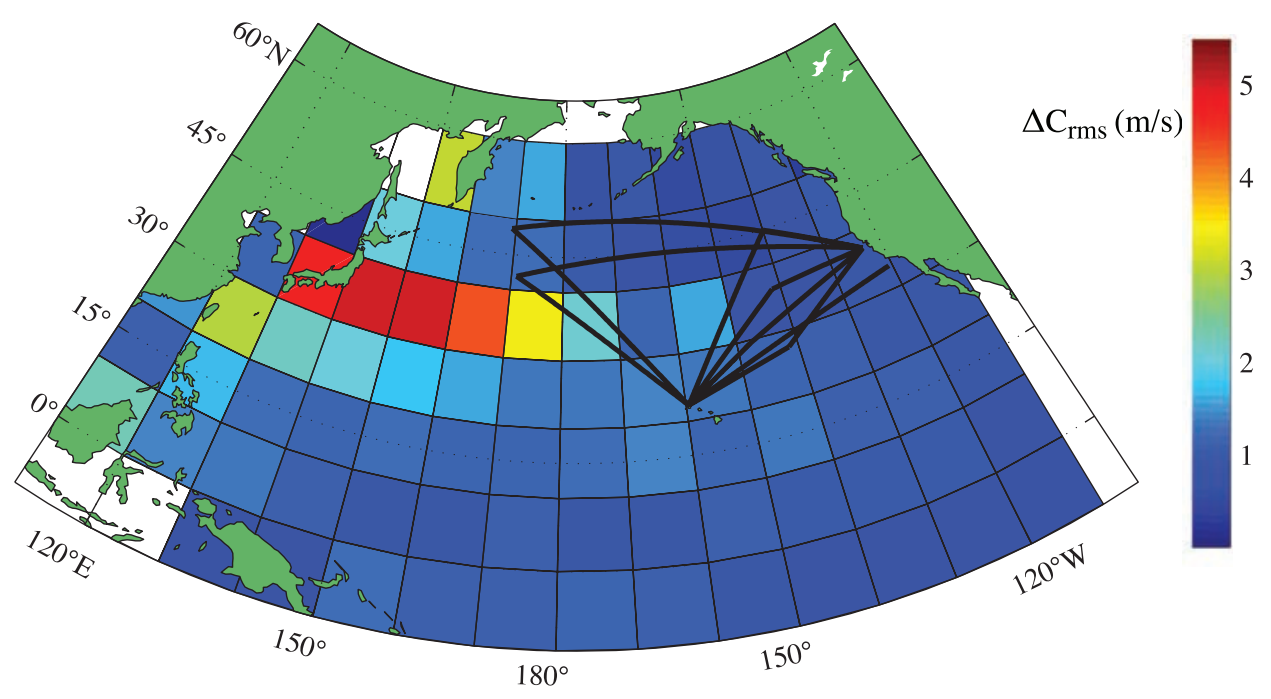

Figure 6. The RMS (in meters per second) of the depth-averaged (150-1000 m) sound-speed perturbations in $10^{\circ} \times 10^{\circ}$ squares in the North Pacific. The perturbations were computed by subtracting annual mean WOA05 sound speed profiles from Argo profiles.

resolving ocean model found that neither mesoscale nor seasonal effects on global-scale acoustic travel times were expected to be so large as to obscure the anticipated signal from global change in the ocean [Semtner and Chervin, 1990; Chiu et al., 1994]. Using coarse-resolution ocean models, Mikolajewicz et al. [1993] made estimates of the ability of global-scale transmissions to detect greenhouse gas-induced climate changes in the presence of decadal time scale fluctuations of the thermohaline circulation. In their simulations, the trend detection probability for any single path and a 1-decade measuring interval turned out to be weak, but improved substantially with the inclusion of additional paths and a 2-decade interval. Similar simulations using a global eddy-resolving model were performed for an acoustic path from Hawaii to Monterey in conjunction with ATOC [Staten et al., 1996]. Travel time variability was estimated to be $0.42 \mathrm{~s}$ RMS for steep rays, due to a combination of seasonal and mesoscale variability, and 0.28 s RMS for near-axial rays, due primarily to seasonal variability. (These estimates are larger than the rough calculations made in the preceding section, because they include seasonal variability.) The observed travel time variability at seasonal and shorter time scales for the Kauai to f path, which is similar to the path for which calculations were made by Staten et al. [1996], is very roughly comparable to that estimated (Figure 2). The mesoscale, seasonal, and interannual variability on the Kauai to k path, which is about the same range, is much larger, however.

[26] Munk and Forbes [1989] estimated that warming induced at the depth of the sound channel axis by $\mathrm{CO}_{2}$ and other greenhouse gases is about $5 \mathrm{~m}^{\circ} \mathrm{C} / \mathrm{a}$. Using (1) and $\partial C / \partial T=3.3 \mathrm{~m} / \mathrm{s}$ per ${ }^{\circ} \mathrm{C}$, the change in travel time corresponding to such warming for the approximately 4Mm-long Kauai to k and Kauai to f paths is roughly $30 \mathrm{~ms} / \mathrm{a}$. The nominal travel time trends for all of the paths are shown in Figure 2. A change of the magnitude estimated by Munk and Forbes [1989] is not seen on the Kauai to $f$ path, where the travel time at the beginning of 1998 is very nearly the same as the travel time at the beginning of 2006, even though a strong warming trend is evident during 20022006. No trend is evident on the Kauai to $\mathrm{n}$ or Kauai to $\mathrm{r}$ paths. On the other hand, the Kauai to o path warmed at roughly the estimated rate.

[27] Weighted least squares fits of linear trends to the time series of average travel times yield the trends in Table 3. As noted above, consistent warming or cooling is not found. All of the secular trends have magnitudes smaller than that of the warming estimated by Munk and Forbes [1989], with uncertainties more or less comparable to the magnitudes of the observed trends. The trends are difficult to determine accurately with a decade of data, given the combination of the small magnitudes of the trends and the large interannual variability.

[28] Small linear trends in travel time would be consistent with the small secular temperature trend in the North Pacific found by Levitus et al. [2005] over roughly the past 50 years. Levitus et al. [2005] reported that the mean temperature over the depth range $0-700 \mathrm{~m}$ in the North Pacific increased by $0.084^{\circ} \mathrm{C}$ over the period $1955-2003\left(0.0018^{\circ} \mathrm{C} / \mathrm{a}\right)$. Although it is not strictly a one-to-one comparison, this trend is roughly one-third of the axial value suggested by Munk and Forbes [1989]. Levitus et al. [2005] also reported that the mean temperature of the North Pacific over the depth range $0-3000 \mathrm{~m}$ increased by $0.018^{\circ} \mathrm{C}$ over the period $(1955-1959)$ to $(1994-1998)\left(0.0005^{\circ} \mathrm{C} / \mathrm{a}\right)$. This trend is only one-tenth of the axial value suggested by Munk and Forbes [1989]. The acoustic rays sample essentially the full

Table 3. Linear Trends From Weighted Least Squares Fits to the Time Series of Average Travel Times ${ }^{\mathrm{a}}$

\begin{tabular}{lccc}
\hline Source & Receiver & Trend $(\mathrm{ms} / \mathrm{a})$ & Trend $\left(\mathrm{m}^{\circ} \mathrm{C} / \mathrm{a}\right)$ \\
\hline Kauai & $\mathrm{k}$ & $-8.6 \pm 4.0$ & +1.6 \\
Kauai & $\mathrm{n}$ & $-3.7 \pm 2.3$ & +1.0 \\
Kauai & $\mathrm{r}$ & $+2.5 \pm 1.8$ & -1.2 \\
Kauai & $\mathrm{f}$ & $+10.1 \pm 2.9$ & -1.7 \\
Kauai & $\mathrm{o}$ & $-12.0 \pm 1.8$ & +4.0 \\
\hline
\end{tabular}

${ }^{\mathrm{a}}$ In the final column, the travel time trends are converted to approximate temperature trends using $\partial C / \partial T=3.3 \mathrm{~m} / \mathrm{s}$ per ${ }^{\circ} \mathrm{C}$. 


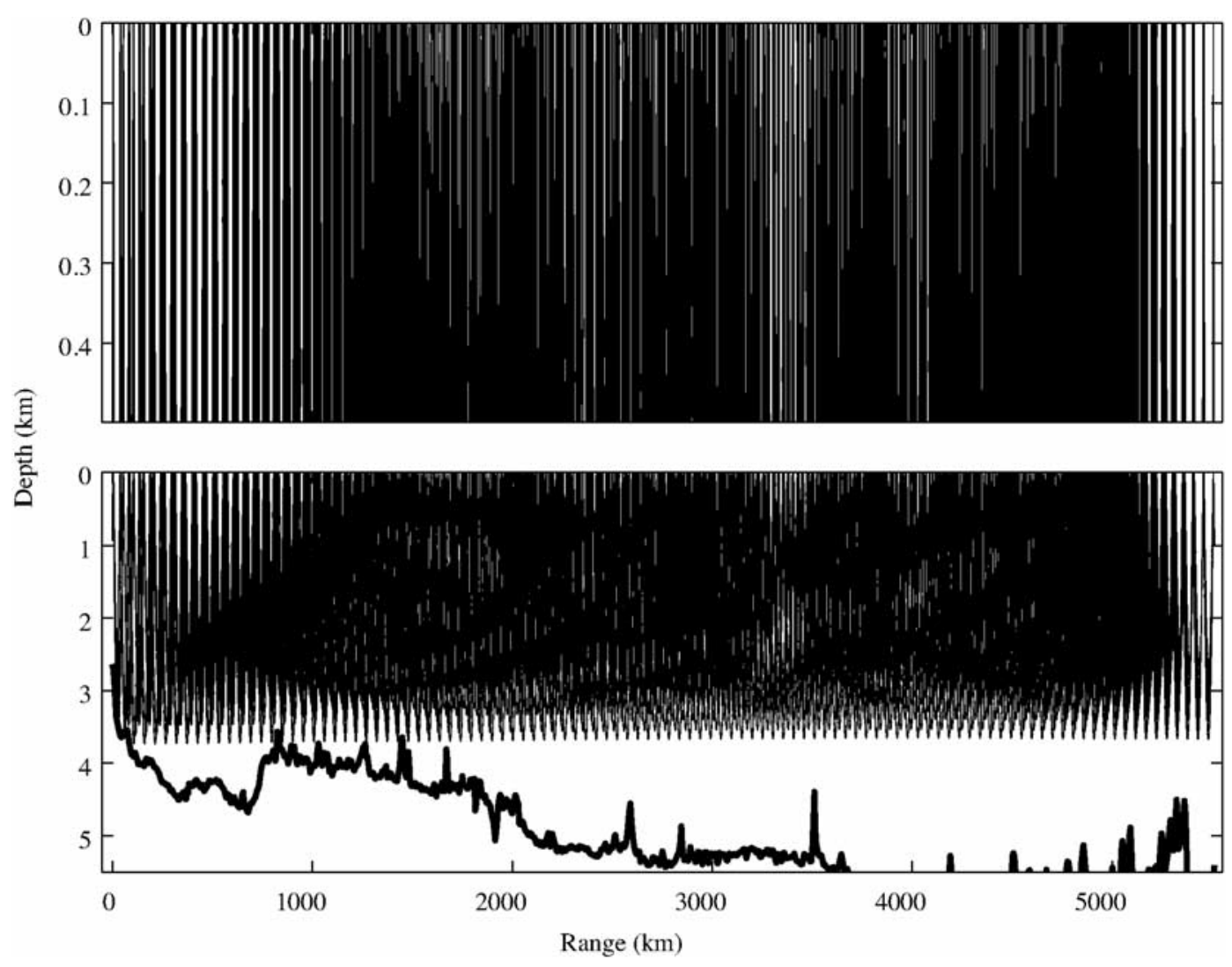

Figure 7. Raypaths of the observed arrivals for transmissions from the Pioneer Seamount source to the notional position of receiver $\mathrm{k}$. (top) An expanded view between the surface and $500 \mathrm{~m}$ depth. (bottom) Full water column, together with the depth of the seafloor.

water column, and it is therefore most appropriate to use the 0-3000 $\mathrm{m}$ value for comparison to the acoustic results. This result is of course specific to the northeast and north central Pacific for which long-range travel time data are available. Global estimates [Willis et al., 2004; Levitus et al., 2005; Gouretski and Koltermann, 2007; Carton and Santorelli, 2008; Domingues et al., 2008] nonetheless indicate that the ocean as a whole has been warming.

\section{Sampling Properties}

[29] The sampling properties associated with the acoustic travel times of the resolved ray arrivals depend on the geometries of the raypaths (eigenrays) connecting the sources and receivers [Munk et al., 1995]. The extent to which the raypaths sample different parts of the water column, i.e., the extent to which the resolved rays have different upper and lower turning points, determines the extent to which the acoustic data can resolve the vertical structure of the sound speed field using inverse methods. The raypath geometries are determined by the vertical structure of sound speed field, in combination with the source and receiver depths, the range, and the bathymetry along the acoustic paths. The raypath geometries for transmissions from the Pioneer Seamount and Kauai sources are somewhat different.

\subsection{Raypath Geometry}

[30] Figure 7 shows the raypaths for transmissions from Pioneer to the notional position of receiver $\mathrm{k}$. The most obvious feature is the existence of raypaths that reflect from the sea surface along the entire acoustic path. This path is largely north of the Subarctic Front, where sound speeds at the surface are lower than those at the seafloor. The rays therefore reflect off the surface before the lower turning points become deep enough to interact with the bottom (refracted-surface-reflected rays). At low acoustic frequencies, reflections from the sea surface are largely specular and suffer little loss. (The wavelength at $75 \mathrm{~Hz}$ is approximately $20 \mathrm{~m}$.) Surface-reflected signals are quite stable and have been routinely used for acoustic tomography and thermometry.

[31] Figure 8 shows the geometry for transmissions from the Kauai source to receiver $\mathrm{f}$. In this case the most obvious feature is the absence of ray sampling in the upper 100$200 \mathrm{~m}$ of the ocean over roughly the first half of the acoustic path. Near Hawaii the warm surface waters have sound speeds that are slightly greater than those at the seafloor. The rays interact with the bottom before the upper turning points become shallow enough to reach the surface. Raypaths that interact with the bottom are attenuated, hence not observed. As the raypaths approach receiver f, however, they begin to sample the upper ocean as near-surface sound speeds decrease in the relatively cold California Current.

[32] For propagation to the northeast from the Kauai source, rays that are purely refracted and rays that interact once with the sea surface and seafloor near the source both contribute to the far-field arrival structure [Vera et al., 2005; 


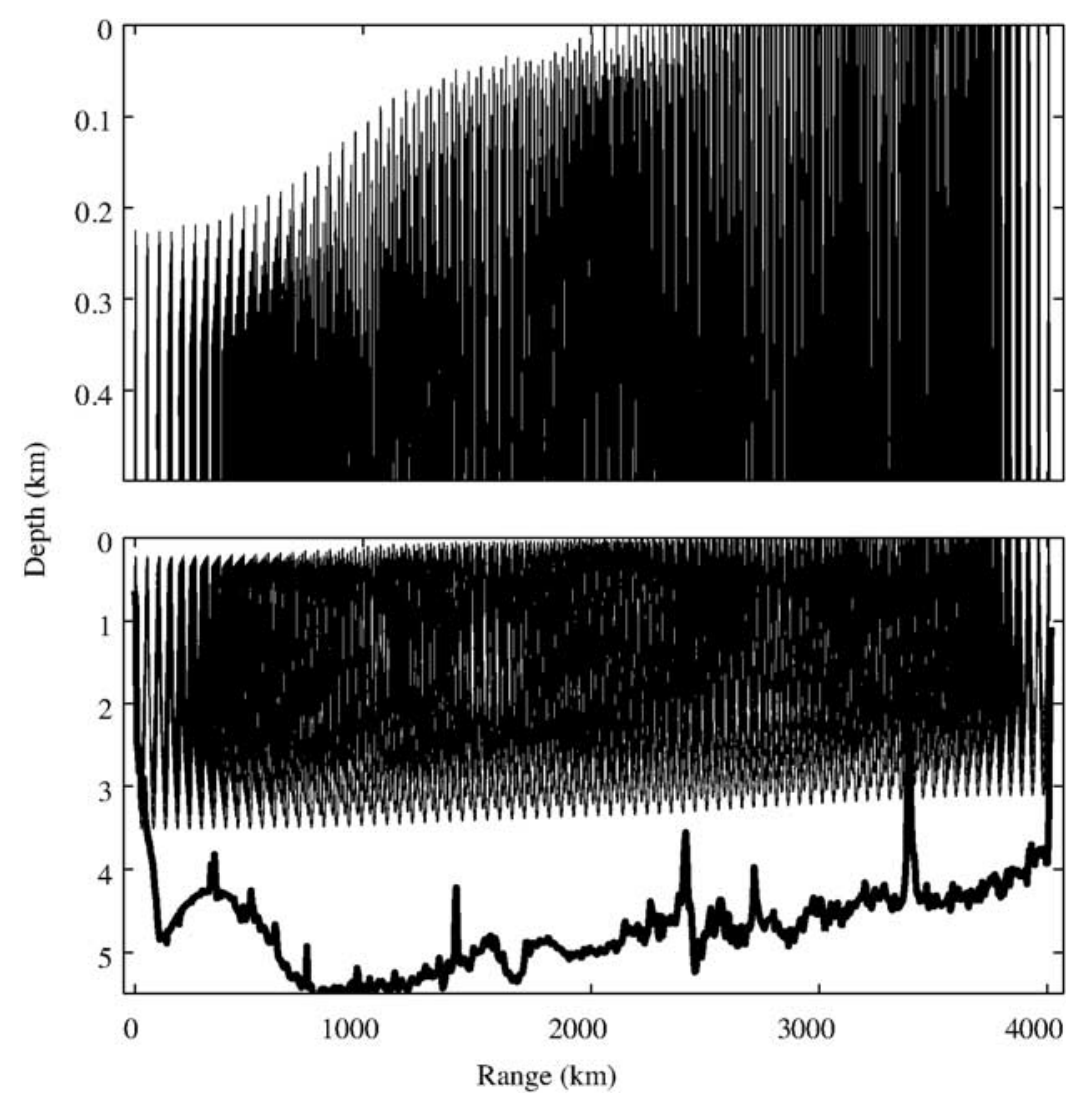

Figure 8. Same as Figure 7, except for transmissions from the Kauai source to receiver $\mathrm{f}$.

Heaney, 2005]. Rays with high launch angles that reflect off the surface and then once off the bottom in front of the source are converted to lower-angle rays due to the bottom slope north of Kauai. These rays then propagate as purely refracted or refracted-surface-reflected rays to distant receivers. This class of rays accounts for the earliest arriving resolved arrivals at long ranges, because it includes steeper angle rays, with shallower upper (and therefore deeper lower) turning points, than are possible for purely refracted rays that do not interact with the seafloor near the source. For the sound speed profiles in the North Pacific, steep rays have shorter travel times than more axial rays. Similar rays do not exist for the Pioneer Seamount source, because the bottom slope in front of the source is much steeper than that north of Kauai.

[33] One implication of the raypath geometries is that the upper ocean in the northern North Pacific and near California is sampled effectively by long-range transmissions, but the upper ocean near Hawaii is not. Another is that raypaths that sample the upper ocean, where seasonal variability is greatest, show strong seasonal signals (e.g., Figure 3, Pioneer Seamount to k). Raypaths that do not sample the upper ocean do not show significant seasonal variability, reflecting instead changes in the deeper ocean (e.g., Figure 2, Kauai to o).

\subsection{Nongeometric Arrivals}

[34] One subtlety in the observed arrival patterns is that the later resolved arrivals at some of the receivers, e.g., $n$ and $\mathrm{o}$, are unexpected because at the times of those arrivals the depth of the receiver is several hundred meters below the predicted arrival pattern [Dushaw et al., 1999]. These nongeometric arrivals are observed to occur at the times of lower cusps in the predicted time fronts, but are much further into the geometric shadow zone than can be accounted for by diffraction [Brekhovskikh and Lysanov, 2003].

[35] Van Uffelen et al. [2009] have found that internal wave-induced scattering is adequate to account for the structure of similar nongeometric arrivals observed on long vertical line array receivers during the 2004-2005 NPAL experiment in the central North Pacific Ocean. Two vertical line array receivers, together virtually spanning the water column, recorded transmissions at 500 and $1000 \mathrm{~km}$ range from broadband $250-\mathrm{Hz}$ sources moored at depths of 750 and $3000 \mathrm{~m}$. Comparisons to parabolic equation simulations for sound speed fields that do not include significant internal wave variability show that early branches of the measured time fronts consistently penetrate as much as 500-800 m deeper into the water column than predicted, even though the parabolic equation simulations include diffractive effects. Parabolic equation simulations incorporating sound speed fluctuations consistent with the GarrettMunk internal wave spectrum accurately predict the observed energy level to within 3-4 dB RMS over the depth range of the shadow-zone arrivals.

[36] Because the nongeometric arrivals observed on the bottom-mounted receivers are stable and can be identified with the cusps in the predicted arrival pattern, the measured travel times are compared here with the travel times of the raypaths associated with the cusps. 


\subsection{Acoustic Scattering}

[37] Receptions at the bottom-mounted receivers are strongly affected by scattering from the seafloor in the vicinity of the array. While bottom interactions complicate the interpretation of the received signals, rays that are upward going at the sources and downward going at the receivers generally provide stable, identifiable arrivals early in the arrival pattern. In addition to bottom scattering, volume scattering due to internal waves and other smallscale oceanographic variability affects the vertical sampling properties of the transmissions. In the northeast and north central Pacific, low-angle rays that sample the ocean in the vicinity of the sound channel axis are strongly scattered by internal waves, producing a complex finalé to the arrival pattern in which individual ray arrivals cannot be resolved [Worcester et al., 1994, 1999]. (This is not necessarily true for other geographic locations, with different sound speed profiles.) One exception is that the pulse termination for near-axial sources and receivers remains relatively unambiguous in the presence of internal wave-induced scattering, providing information on the near-axial ocean. Even when bottom-mounted receivers are located relatively close to the depth of the sound channel axis, however, bottomscattered energy makes it impossible to observe the pulse termination that would be evident on a midwater receiver [Dushaw et al., 1999]. The result is that at long ranges only relatively steep arrivals are resolvable and identifiable on the bottom-mounted receivers, limiting the extent to which the vertical structure of the sound speed field can be determined from the acoustic data.

\subsection{Inverse Methods and Data Assimilation}

[38] Although inverse methods have been applied to long-range travel time data from both bottom-mounted and VLA receivers to estimate sound speed (temperature) [Baggeroer et al., 1998; Dushaw, 1999; Worcester et al., 1999], the combination of limited vertical resolution and the strongly range-dependent sampling of many of the longrange raypaths, particularly those for transmissions from the Kauai source, makes it difficult to compare temperatures derived from acoustic data to more conventional data types. In this article, direct comparisons will therefore be made between the measured travel times and equivalent travel times calculated using sound speed fields derived from various estimates of the temperature and salinity fields in the North Pacific. This comparison represents a first step toward using data assimilation methods to directly constrain dynamic ocean models using acoustic travel times. Although the problem of combining integral tomographic data with time-evolving models does not differ in any fundamental way from the problem of using other data types, the approximate data assimilation methods employed in earlier efforts [Menemenlis et al., 1997; Baggeroer et al., 1998] were suboptimal and did not retain the full information content of the integral acoustic data. Approximate data assimilation methods, for example, nudging, optimized for measurements localized in physical space are generally inappropriate because they do not preserve the nonlocal tomographic information [Cornuelle and Worcester, 1996]. More rigorous data assimilation techniques, however, such as the adjoint method, naturally take into account the precise sampling properties of each data type [Wunsch and Heimbach, 2006].

\section{Observed and Calculated Acoustic Travel Times: Objective Analysis of Satellite Altimetric Height and In Situ Temperature Profiles}

[39] In this section, measured acoustic travel times are compared to those computed using estimates of upper-ocean temperature profiles produced by an objective analysis procedure that combines satellite altimetric height with in situ temperature profiles. Willis et al. [2004] produced estimates of subsurface temperature variability on a $1^{\circ} \times$ $1^{\circ}$ grid at 3-month intervals with $10-\mathrm{m}$ resolution from the surface to $750 \mathrm{~m}$. The estimates were initially produced from mid-1993 through mid-2003. Lyman et al. [2006] extended the estimates through late 2005.

[40] It was subsequently discovered that there was a problem with a number of Argo profiling floats deployed between mid-2003 and 2006 that resulted in spuriously cold temperature profiles [Willis et al., 2007]. In addition, temperature profiles from expendable bathythermograph (XBT) probes were found to have a time-varying warm bias of $0.2-0.4^{\circ} \mathrm{C}$ due to changes in the probe fall rate likely associated with small manufacturing changes at the factory [Gouretski and Koltermann, 2007; Wijffels et al., 2008]. Because the Argo floats providing spuriously cold temperature profiles were deployed primarily in the Atlantic Ocean, this problem should not significantly affect the comparisons presented here for the North Pacific Ocean. The biases in the XBT profiles will affect the comparisons shown here, however. The measured acoustic travel times are not subject to similar calibration issues, as they depend only on the accurate measurement of time. The estimates of subsurface temperature variability are currently being revised, but revised estimates have not yet been published.

[41] Willis et al. removed the time mean (January 1993 through December 2002) and the seasonal cycle from both the altimeter and in situ data prior to analysis. For the altimeter data, the seasonal cycle was estimated at each grid point from 3-month bin averages over all years of altimeter data. For the in situ profile data, the seasonal cycle was estimated from 3-month bin averages of the seasonal anomalies from the World Ocean Atlas 2001. Willis et al. then generated maps of temperature using the "difference estimate" [Willis et al., 2003]. The estimate is an objective map of temperature using as the initial guess a "synthetic estimate," which is derived from the regression of altimetric height onto profiles of temperature extending from the surface to $750 \mathrm{~m}$ depth. In regions where temperature profile data are abundant, the objective map brings the initial guess into agreement with the in situ data. In regions with no in situ data the difference estimate reverts to the synthetic estimate, based solely on altimetric height. The mapping procedure was used to create 1-year average anomalies at 3-month intervals.

[42] Full-depth sound speed fields are needed in order to compute acoustic travel times. Annual mean temperature and salinity fields from WOA05 were therefore combined with the 0 - to $750-\mathrm{m}$ temperature profiles using the procedures described in Appendix B in order to construct fulldepth temperature and salinity fields. Sound speed was then 


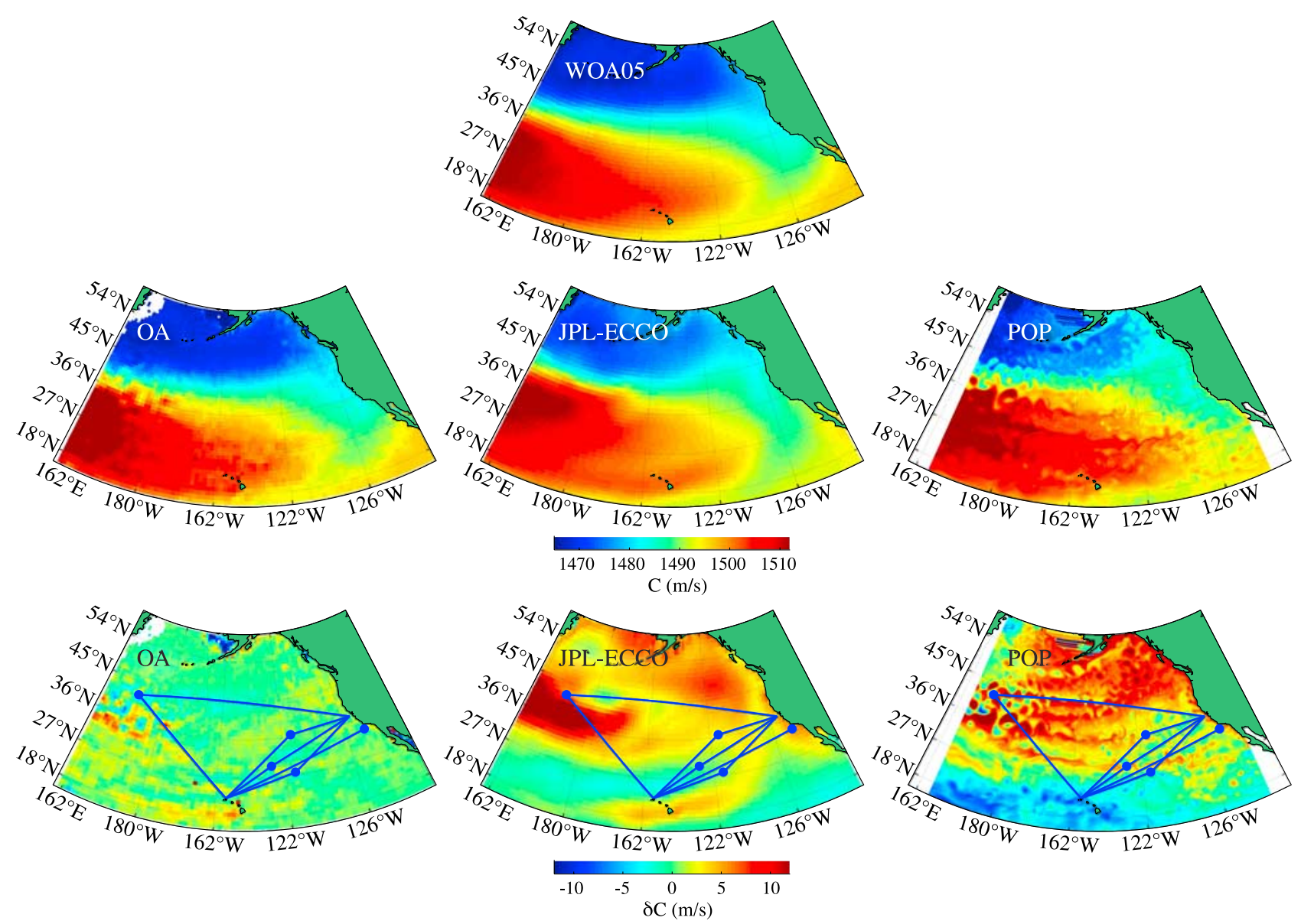

Figure 9. Sound speed at $300 \mathrm{~m}$ depth in the North Pacific Ocean derived from WOA05, from estimates of upper-ocean temperature profiles produced by an objective analysis $(\mathrm{OA})$ procedure that combines satellite altimetric height with in situ temperature profiles, from the Jet Propulsion LaboratoryEstimating the Circulation and Climate of the Ocean (JPL-ECCO) solution, and from a high-resolution integration of the Parallel Ocean Program (POP) model. The WOA05 field is the annual mean, the objective analysis is for winter 2003, and the JPL-ECCO and POP estimates are for January 2003. (bottom) Differences between the fields derived from the various estimates and the field derived from the annual mean WOA05.

computed from these fields. The sound speed field at $300 \mathrm{~m}$ depth in the North Pacific Ocean in Winter 2003 is compared in Figure 9 with the annual mean sound speed field derived from WOA05. The character of the two fields is generally similar, as expected. The difference between the two fields contains a substantial amount of mesoscale structure, however, even though the product developed by Willis et al. [2003] includes both temporal and spatial averaging (Figure 9). This small-scale structure is present because the spatially lagged covariance function used to construct the objective maps consists of both a short-lengthscale Gaussian component and a larger-scale exponential function,

$$
\begin{aligned}
C(x)= & 0.22 \exp (-|x| / 920 \mathrm{~km}) \\
& +0.78 \exp \left(-(x / 100 \mathrm{~km})^{2}\right) .
\end{aligned}
$$

The short-length-scale component allows for mesoscale variability and other small-scale structure.
[43] In Figure 10, the travel times computed for the Kauai source using the objective maps are compared with the measured travel times, after removing the means. The computed travel times do not reflect the seasonal cycle, because it was removed from the altimeter and in situ data prior to analysis. They also do not reflect other variability at periods shorter than a year, because the mapping procedure was used to produce 1-year average anomalies. In contrast, the measured travel times are daily averages and therefore include both the seasonal cycle and higher-frequency variability.

[44] Travel times computed for the Pioneer Seamount source are not shown. The relatively short duration of the measured time series for the Pioneer Seamount source make comparisons with travel times computed from the 1-year average temperature anomalies produced by the objective analysis procedure problematic.

[45] For some of the paths from the Kauai source, the combination of satellite altimetry and in situ profile data seems to provide adequate sampling of the ocean to reproduce the measured low-frequency trends in the travel times. 


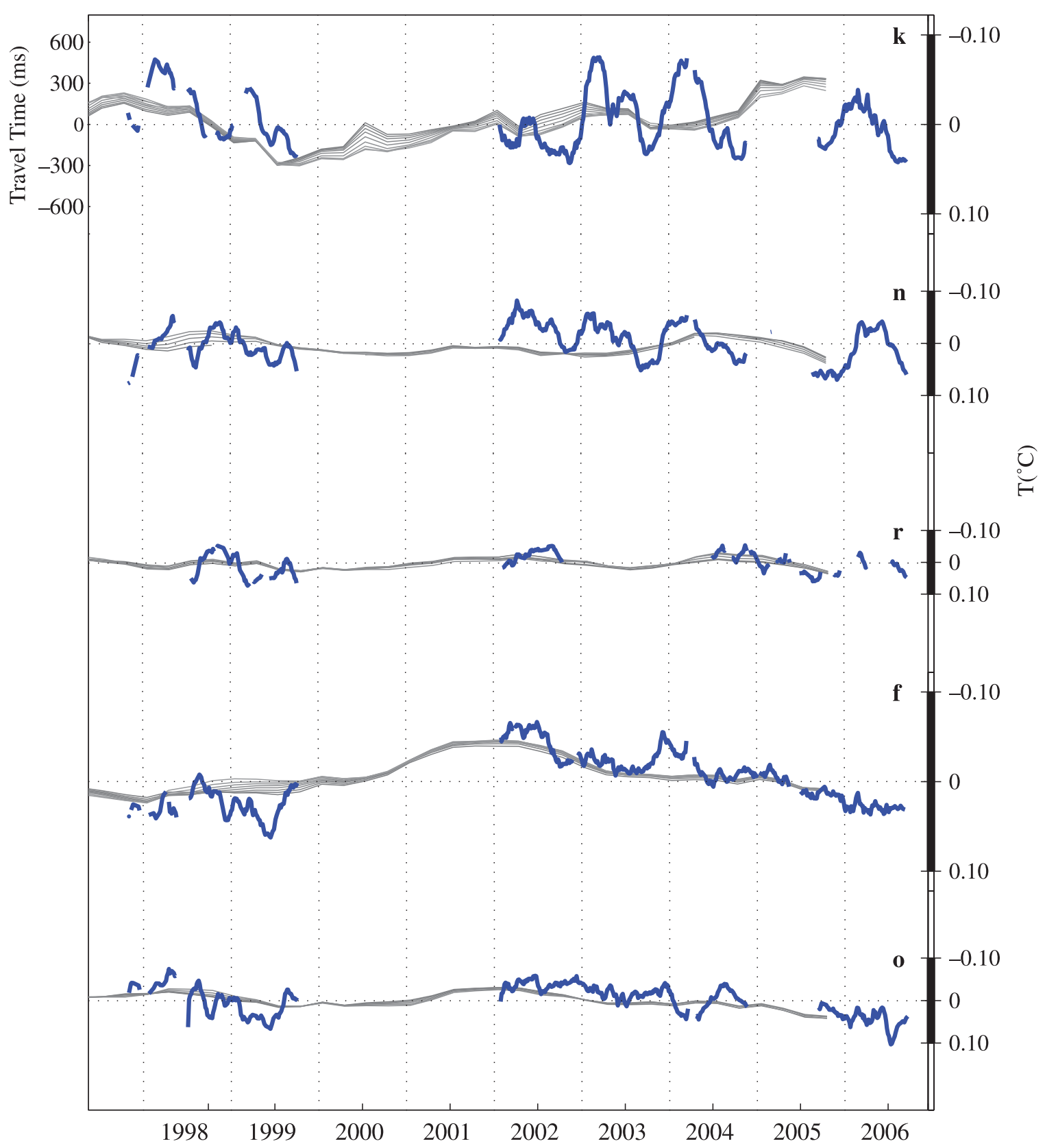

Figure 10. Comparison of measured travel times for transmissions from Kauai (blue) with travel times calculated using estimates of upper-ocean temperature profiles produced by combining satellite altimetric height with in situ temperature profiles (gray). The time means have been removed from all of the time series. Approximate estimates of temperature perturbations averaged along the raypaths inferred from the travel times are shown on the right-hand axis.

The computed travel times for the Kauai to $\mathrm{f}$ path, for example, show a warming trend (shorter travel times) from 2002 to 2005 that is in general agreement with the measured travel times. Warming trends during 2002 to 2005 are also seen in both the computed and measured travel times for the Kauai to o path, which roughly corresponds to the western one-third to one-half of the Kauai to f path (Figure 1). Note that this path is substantially shorter than the Kauai to $f$ path, and the travel time changes are therefore expected to be smaller even if the warming were uniformly distributed along the Kauai to $\mathrm{f}$ path. On another path, the computed travel times from Kauai to $\mathrm{k}$ seem to generally reflect the warming trend during 1998-1999 evident in the measured travel times, although the seasonal and higher-frequency variability in the measured travel times on this path is so large that it is difficult to draw firm conclusions about the similarity of the low-frequency variability in the two series, particularly later in the series. In other cases, the computed travel times do not seem to reproduce the measured travel times, however. On the Kauai to $n$ path, for example, the measured travel times show a slight warming during $2002-$ 2004 that is not present in the computed travel times.

[46] Some of the variability with durations shorter than a year present in the measured travel times is substantial, e.g., 
the warming in the first half of 1999 and the cooling during winter 2003-2004 on Kauai to f. The altimetry and in situ data often do not seem to reflect even smoothed versions of these events.

\section{Observed and Calculated Acoustic Travel Times: Jet Propulsion Laboratory-ECCO Solution}

[47] The objective mapping techniques used in the previous section to obtain upper-ocean temperature fields from satellite altimetric height and temperature profile data treat each time increment independently, without consideration of ocean dynamics. In this section, the measured acoustic travel times are compared to those computed using estimates of the time-dependent ocean temperature and salinity fields obtained from a near-real-time analysis provided by the Estimating the Circulation and Climate of the Ocean (ECCO) project. This particular ECCO analysis was produced at the Jet Propulsion Laboratory (JPL) by constraining the Massachusetts Institute of Technology general circulation model (MITgcm) [Marshall et al., 1997] with a variety of data, including sea surface height from satellite altimetry and in situ temperature profile data. The resulting fields are therefore required to be consistent with timedependent ocean dynamics, as embodied in the MITgcm, and with the altimetric and temperature profile data to within prior model and data uncertainties.

[48] The JPL-ECCO near-real-time analysis is based on a quasiglobal $\left(73^{\circ} \mathrm{S}\right.$ to $\left.73^{\circ} \mathrm{N}\right)$ configuration of the MITgcm with a horizontal grid that has 360 zonal and 224 meridional cells. Zonal grid spacing is $1^{\circ}$ of longitude. Meridional grid spacing is $0.3^{\circ}$ of latitude within $10^{\circ}$ of the equator and increases to $1^{\circ}$ of latitude poleward of $22^{\circ} \mathrm{N}$ and $22^{\circ} \mathrm{S}$. There are 46 levels in the vertical with thicknesses of $10 \mathrm{~m}$ in the top $150 \mathrm{~m}$, gradually increasing to $400 \mathrm{~m}$ near the bottom. The model is forced at the surface with 12-h wind stress estimates and with daily heat and freshwater fluxes from the National Centers for Environmental Prediction (NCEP)-National Center for Atmospheric Research (NCAR) reanalysis data [Kalnay et al., 1996], with some minor modifications. The JPL-ECCO data-constrained solution used in this study is the "kf049f" Kalman filter solution (available at http://ecco.jpl.nasa.gov/cgi-bin/nphdods/datasets/kf049f/) up through the end of 2005. The data used to constrain the baseline integration are observations of sea surface height and a collection of vertical temperature profiles, including data from XBTs, from the Tropical Atmosphere Ocean (TAO) array, and from the Argo global array of free-drifting profiling floats. The constrained JPL-ECCO analysis is obtained in two steps. In a first step, the Green's function approach of Menemenlis et al. [2005] is used to calibrate the model's internal mixing parameters, the initial temperature and salinity conditions, the sea surface temperature and salinity relaxation coefficients, and the time mean surface wind stress. In a second step, the approximate Kalman filter of Fukumori [2002] is used to correct residual adiabatic time-dependent errors. Additional details describing the model implementation are given in Menemenlis et al. [2005].

[49] The spuriously cold temperature profiles from a number of Argo floats deployed between mid-2003 and

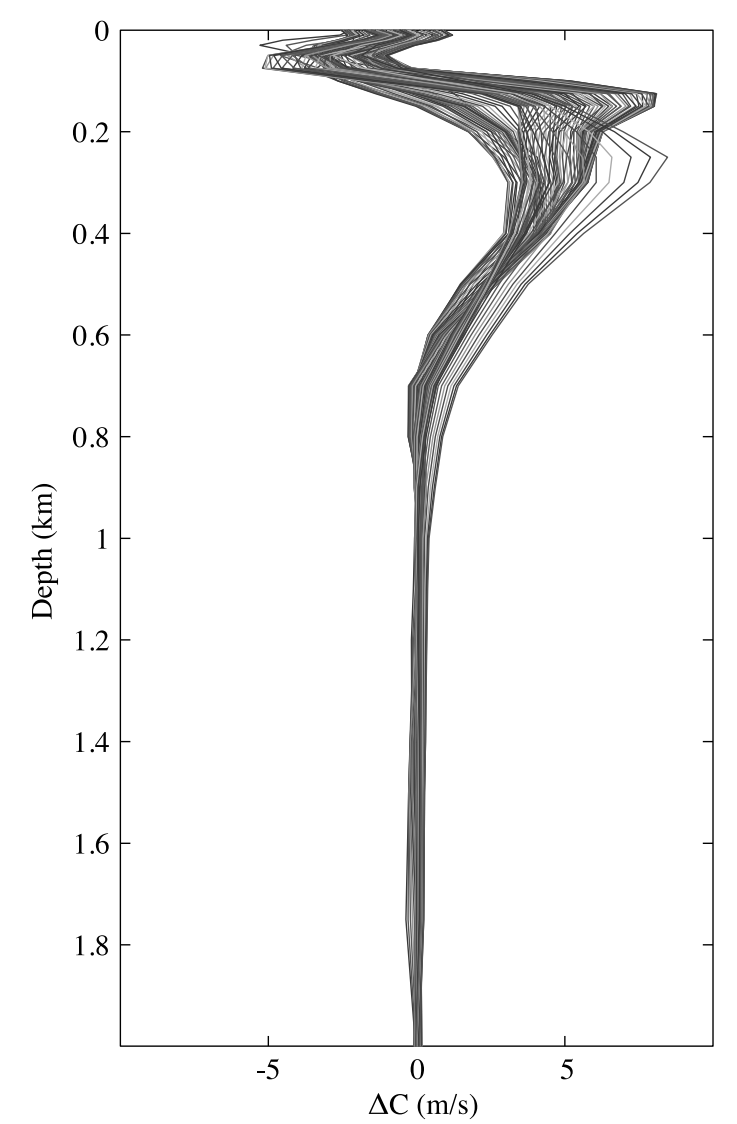

Figure 11. Vertical profiles of the differences in sound speed between the time mean of the JPL-ECCO solution and the annual mean WOA05 for 100 equally spaced sound speed profiles along the Pioneer to $\mathrm{k}$ acoustic path. Positive values indicate that the JPL-ECCO solution has higher sound speeds.

2006 and the time-varying warm bias in temperature profiles from XBT probes affect the JPL-ECCO solution, as well as the objective analysis in the last section. Although the problem in the Argo floats likely does not significantly affect the comparisons presented here, the biases in the XBT profiles will affect the comparisons, as discussed in the previous section. The JPL-ECCO solutions are currently being revised, but revised estimates have not yet been published.

[50] The ocean sound speed field at $300 \mathrm{~m}$ depth computed using the temperature and salinity fields provided by the JPL-ECCO solution in January 2003 is compared in Figure 9 with the annual mean sound speed field derived from WOA05. This implementation of the MITgem is not eddy-resolving, and the sound speed field is therefore relatively smooth. There are surprisingly large geographic areas over which the JPL-ECCO solution and WOA05 differ, however, as can be seen most clearly in the difference field shown in Figure 9. The entire Gulf of Alaska is warmer (higher sound speed) at $300 \mathrm{~m}$ in the JPL-ECCO solution than in WOA05, for example. A large area to the northwest of the Hawaiian Islands is also substantially warmer in the JPL-ECCO solution.

[51] Initial efforts to use the sound speed fields derived from the JPL-ECCO solution to compute acoustic travel 


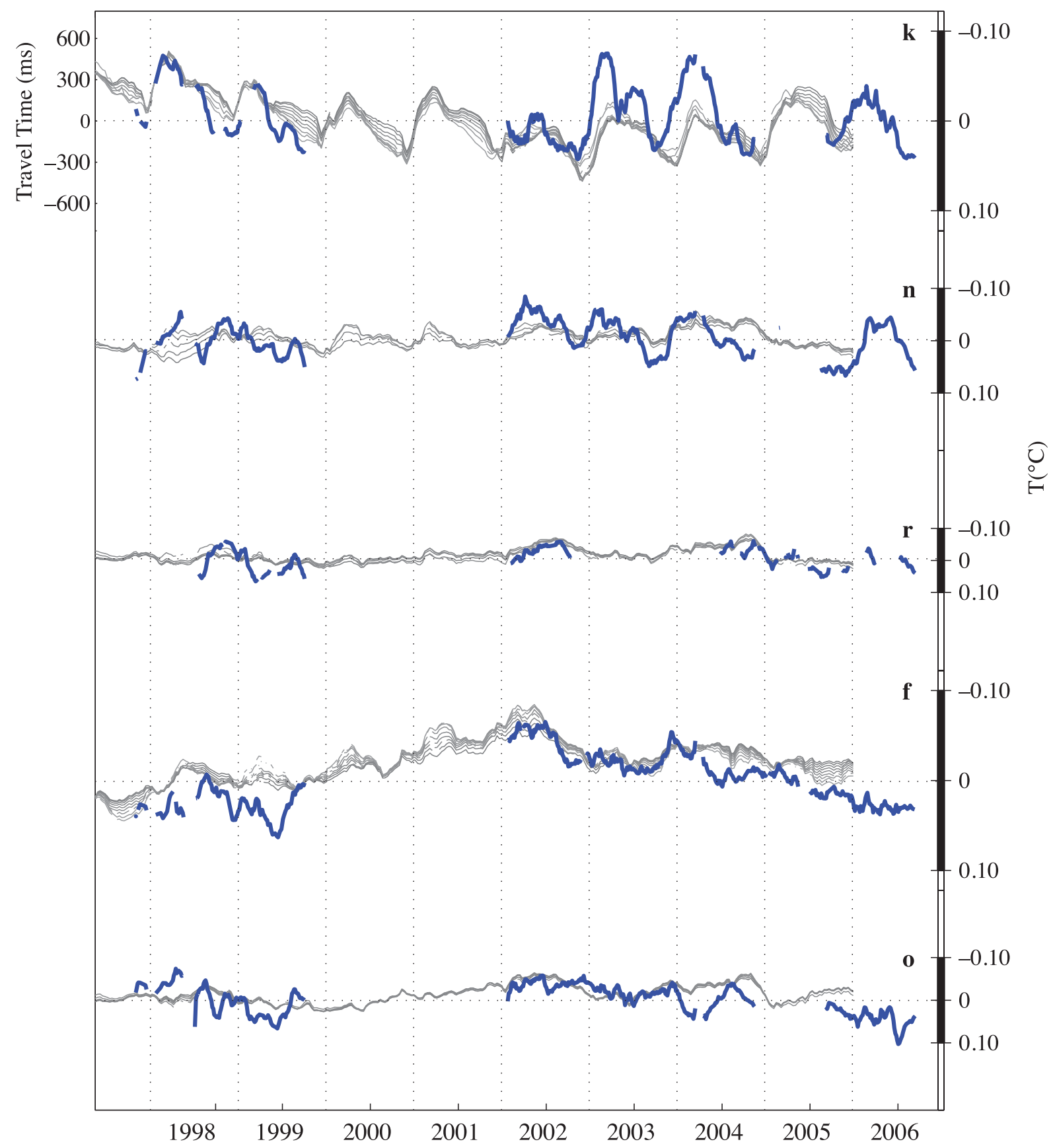

Figure 12. Comparison of measured travel times for transmissions from Kauai (blue) with travel times calculated using temperature and salinity fields from the JPL-ECCO solution (gray). The time means have been removed from all of the time series. Approximate estimates of temperature perturbations averaged along the raypaths inferred from the travel times are shown on the right-hand axis.

times for comparison with the measured travel times failed. The predicted arrival patterns at the various receivers did not match the observed arrival patterns. No such difficulty was encountered when using WOA05 fields for acoustic propagation calculations in section 2 . While this difficulty is related to the large-scale differences between the JPLECCO solution and WOA05 noted above, the critical parameter for acoustic propagation calculations is the vertical sound speed gradient. Vertical profiles of the difference between the time mean of the JPL-ECCO solution and the annual mean from WOA05 along the Pioneer Seamount to $\mathrm{k}$ path reveal substantial differences (Figure 11). The JPLECCO solution has slower sound speeds by up to about $6 \mathrm{~m} / \mathrm{s}$ than WOA05 in the upper $100 \mathrm{~m}$ (i.e., the JPL-ECCO solution is colder by roughly $1.5^{\circ} \mathrm{C}$ ), but has higher sound speeds by up to about $8 \mathrm{~m} / \mathrm{s}$ from $100 \mathrm{~m}$ down to roughly $600 \mathrm{~m}$ (i.e., the JPL-ECCO solution is warmer by roughly $2{ }^{\circ} \mathrm{C}$ ). The resulting vertical gradients in the JPL-ECCO solution are sufficiently unrealistic that acoustic calculations using the derived sound speed fields are also unrealistic. In order to proceed, the time means of the JPL-ECCO temperature and salinity fields were subtracted from the model 


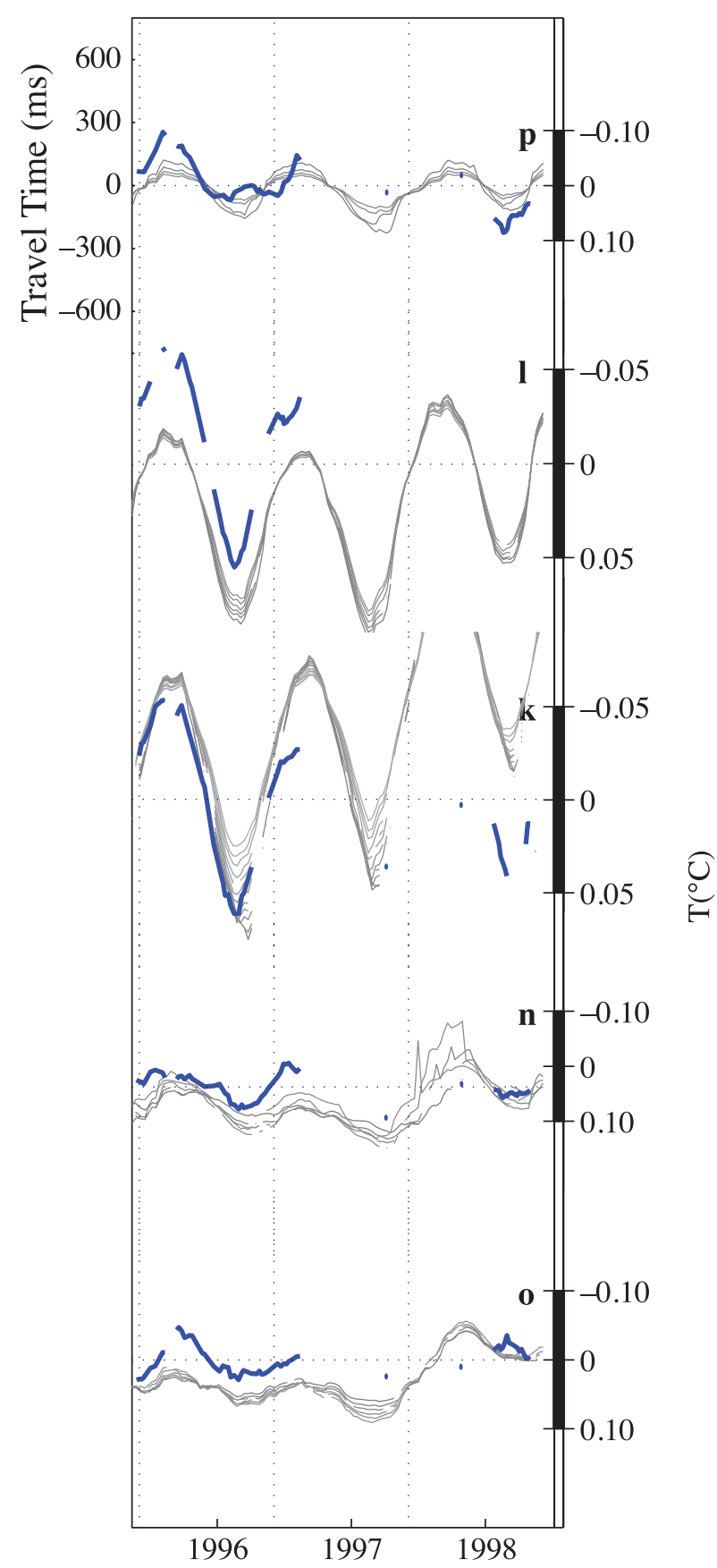

Figure 13. Same as Figure 12, except for transmissions from Pioneer Seamount. The calculated travel times for Pioneer to $\mathrm{k}$ are not plotted when they deviate too far from the mean.

fields and replaced with annual mean fields from WOA05. The predicted arrival patterns then match the measured arrival patterns, and the resulting travel times can be compared. The temporal variability of sound speed does not significantly affect the nature of the arrival pattern. This procedure implicitly assumes that although the time mean state of the JPL-ECCO solution is unrealistic, the variability is sufficiently constrained by the data to be meaningful.

[52] The travel times computed for the JPL-ECCO solution are compared with the measured travel times for transmissions from the Kauai and Pioneer Seamount sources in Figures 12 and 13, respectively, again after removing the means. The travel times computed from the JPL-ECCO solution show the seasonal cycle and substantial highfrequency variability, unlike those derived from the objective maps in the previous section. The computed and measured travel times have some similarities, but also substantial differences. On long time scales, for example, the computed travel times for the Kauai to $f$ path show a warming trend (shorter travel times) from 2002 to 2005 that is similar to that seen in the measured travel times, although the decrease in travel time predicted using the JPL-ECCO solution is somewhat less than that measured. This result is not unlike that obtained using the objective maps, which is perhaps not surprising, as both use sea surface height and profile data in generating ocean estimates. In the more fragmentary results for the Pioneer Seamount to k path, however, the measured travel times show little change between late 1996 and late 1998, while the computed travel times show a large trend. As was the case for the objective maps, the JPL-ECCO solutions do not show consistent trends over the nearly decade-long time period. On shorter time scales, the size of the computed and measured seasonal cycles on the paths from Pioneer Seamount to 1 and $k$ are in reasonable agreement in 1996. The measured seasonal signal on the Kauai to k path during 2003-2004 is nearly twice the computed signal, however. In general, the variability at periods shorter than the seasonal cycle does not seem to be well represented in travel times computed from the JPL-ECCO solution, particularly for the transmissions from Kauai. In summary, the differences have magnitudes comparable to a large fraction of the seasonal cycle, indicating that acoustic travel times could provide significant constraints on the large-scale variability in the JPLECCO solution, in addition to the constraints imposed by the data that have already been assimilated.

\section{Observed and Calculated Acoustic Travel Times: Parallel Ocean Program Model}

[53] In this section, measured acoustic travel times are compared to those computed using monthly snapshots of the time-dependent ocean temperature and salinity fields obtained from a high-resolution integration of the POP model for the period 1979-2003 [Maltrud and McClean, 2005; McClean et al., 2006]. The POP model [Smith et al., 1992; Dukowicz et al., 1993; Dukowicz and Smith, 1994] is a z-level coordinate ocean model with an implicit free surface. The results presented here are from a $0.1^{\circ}, 40$-level global POP integration configured on a nonuniform, general curvilinear grid in which the North Pole is rotated smoothly into Hudson Bay. POP is able to resolve mesoscale ocean variability over much of the domain, which gives much smaller-scale temperature and salinity variability than the non-eddy-resolving JPL-ECCO solution. POP was forced with surface boundary conditions, primarily from the NCEP-NCAR reanalysis [Kalnay et al., 1996]. In contrast to the JPL-ECCO solutions used in the previous section, POP is not constrained with satellite or in situ data. Additional details describing the model implementation are given by Maltrud and McClean [2005] and can also be found at http://climate.acl.lanl.gov. 


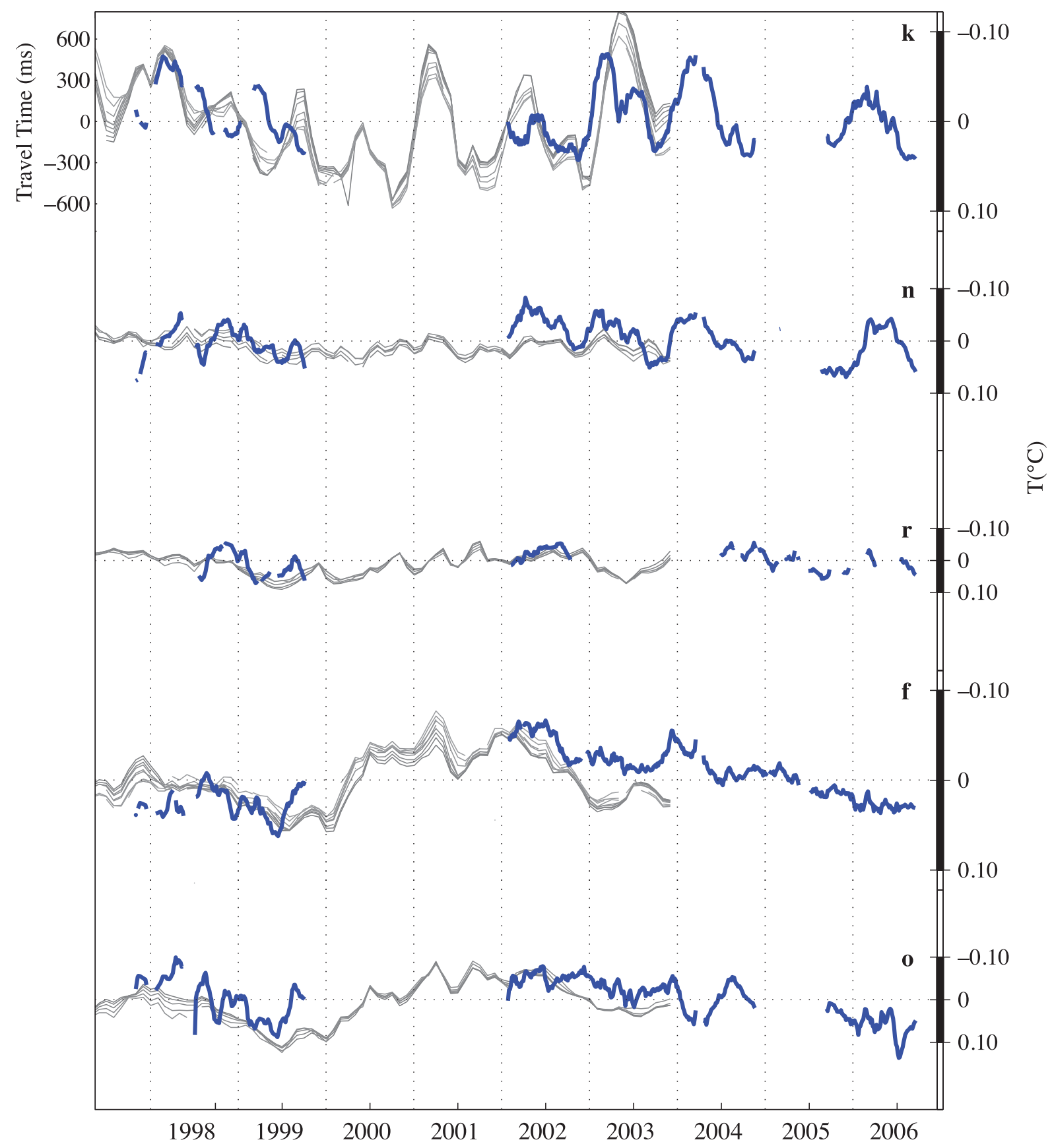

Figure 14. Comparison of measured travel times for transmissions from Kauai (blue) with travel times calculated using temperature and salinity fields from the POP model (gray). The time means have been removed from all of the time series. Approximate estimates of temperature perturbations averaged along the raypaths inferred from the travel times are shown on the right-hand axis.

[54] The ocean sound speed field at $300 \mathrm{~m}$ depth derived from the POP estimate for January 2003 is compared in Figure 9 with the annual mean derived from WOA05. As expected, the POP estimate contains much more small-scale structure than either WOA05 or the JPL-ECCO solution. As was the case for the JPL-ECCO solution, there are large geographic areas over which the POP estimate and WOA05 differ. The Gulf of Alaska is substantially warmer in the POP estimate than in WOA05, not unlike the JPL-ECCO solution. The area around the Hawaiian Islands is substantially colder than in WOA05. The differences between the
POP estimate and WOA05 bear little resemblance to the differences between the estimate made combining altimetric and in situ profile data and WOA05.

[55] Initial efforts to use the sound speed fields derived from the POP model to compute acoustic travel times failed to give useful results. The predicted and measured arrival patterns did not match. The vertical gradients of the timemean of sound speed in the upper ocean from the POP estimate are unrealistic, as was the case for the JPL-ECCO solution. In order to proceed, the time means of the POP temperature and salinity fields were subtracted from the 


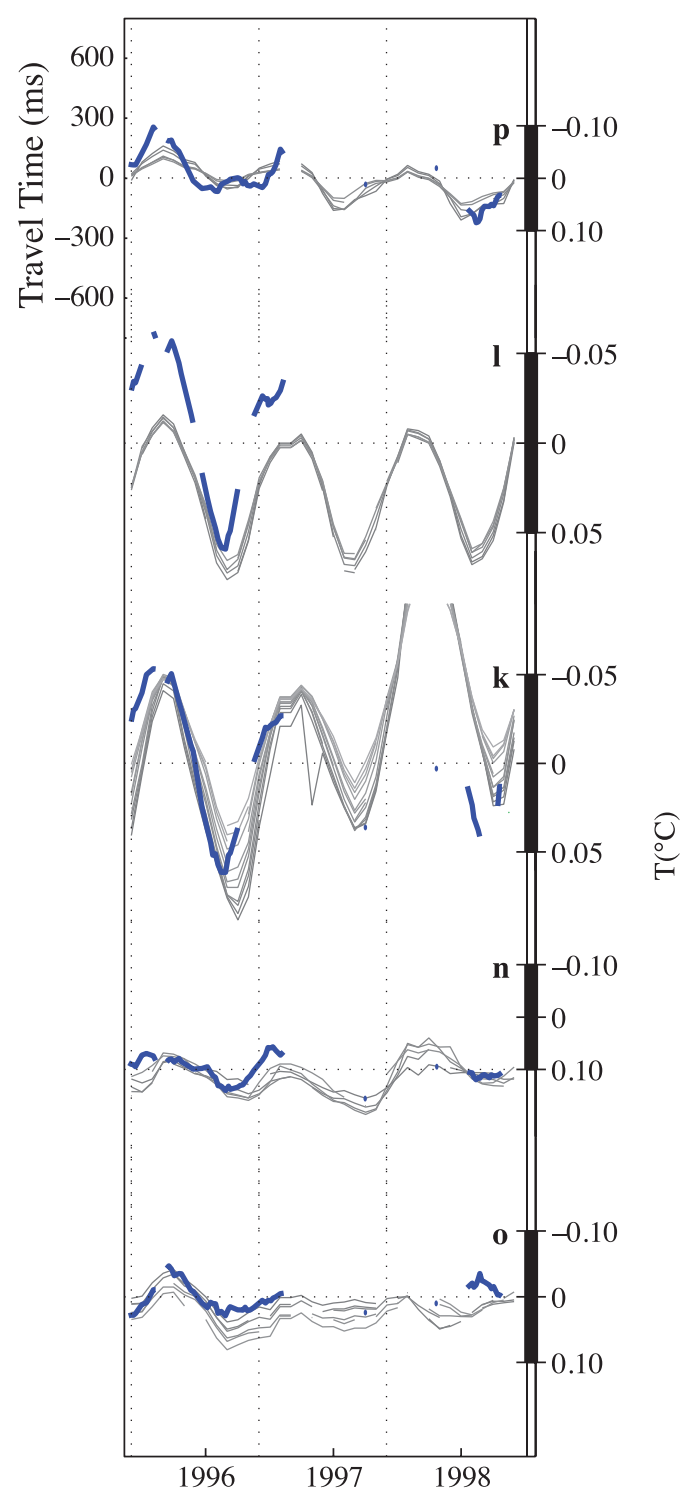

Figure 15. Same as Figure 14, except for transmissions from Pioneer Seamount. The calculated travel times for Pioneer to $\mathrm{k}$ are not plotted when they deviate too far from the mean.

model fields and replaced with annual mean fields from WOA05, as was done for the JPL-ECCO solution.

[56] Figures 14 and 15 compare the travel times computed for the POP model with the measured travel times, after removing the means. Comparisons are not possible for the full duration of the acoustic time series, because POP estimates are only available through 2003 . The comparisons are again mixed. Somewhat surprisingly, given that it is not constrained by satellite or in situ data, the POP model is comparable to the JPL-ECCO solution in the ability to estimate the long-term variability in the travel times. In fact, the POP estimates for the fragmentary Pioneer Seamount to $\mathrm{k}$ path seem more in accord with the measured travel times than the JPL-ECCO solution, which contains an unrealistically large trend. Again, the POP estimates do not show consistent trends over the nearly decade-long time period. On shorter time scales, POP somewhat overesti- mates the large seasonal cycle observed in the travel times during 2003, while the JPL-ECCO solution underestimates it. Interestingly, although the POP model is mesoscale resolving, the travel times derived from it do not seem to contain substantially more short-timescale variability than the non-eddy-resolving JPL-ECCO solution, reflecting the inherent averaging properties of the acoustic travel times. The differences between the measured and computed travel times have magnitudes comparable to a large fraction of the seasonal cycle, as was the case for the JPL-ECCO solution.

[57] The relative contributions of temperature and salinity to travel time variability can be assessed using the POP estimates. Figure 16 shows range- and depth-average $(0-$ $1000 \mathrm{~m}$ ) temperature and salinity from the POP model for Kauai to k. The largest salinity fluctuation occurred in 2003, at the time when a large and rapid travel time increase occurred. At this time, there are large decreases in salinity and temperature. The effect of these fluctuations on density (and therefore sea surface height) is relatively small, because the changes in temperature and salinity compensate for one another. This is not the case for travel times, which mostly reflect temperature. Even in this extreme case, salinity fluctuations are only responsible for $1.4 \%$ of the total variation in sound speed, confirming that it is appropriate to interpret travel time fluctuations in terms of temperature fluctuations averaged along the raypaths.

\section{Summary and Discussion}

[58] One of the more surprising results from the comparisons reported here is that the JPL-ECCO and POP
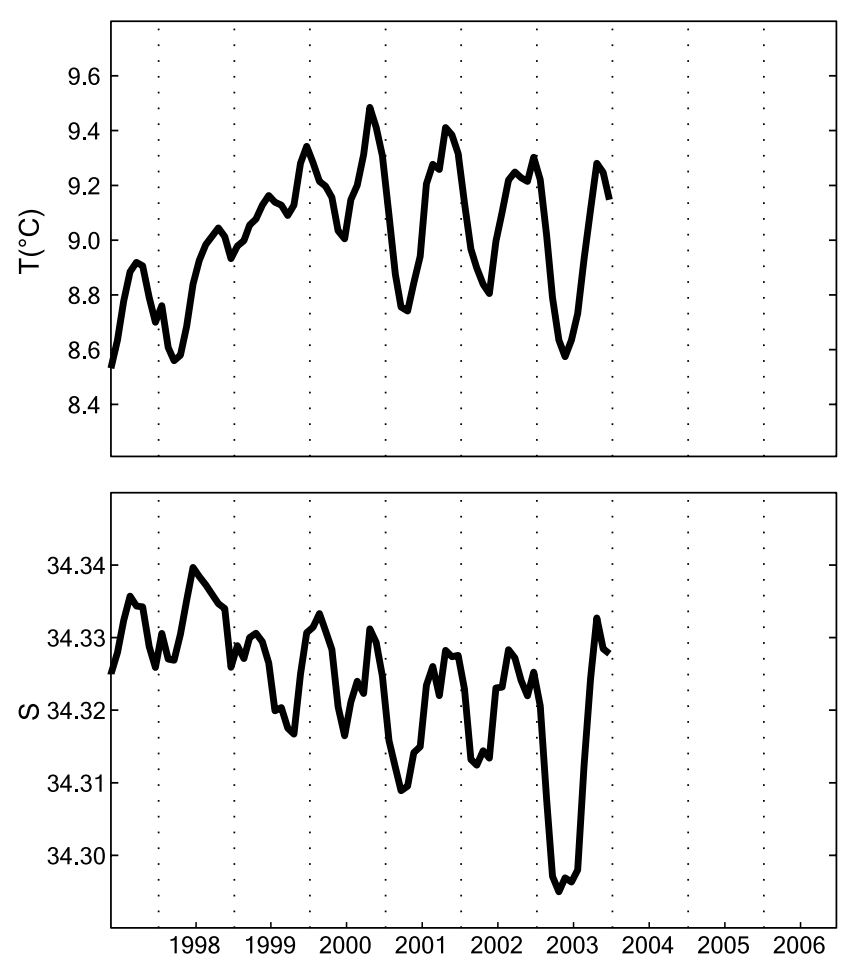

Figure 16. Range- and depth-average $(0-1000 \mathrm{~m})$ (top) temperature and (bottom) salinity for the Kauai to k path computed using the POP model. 


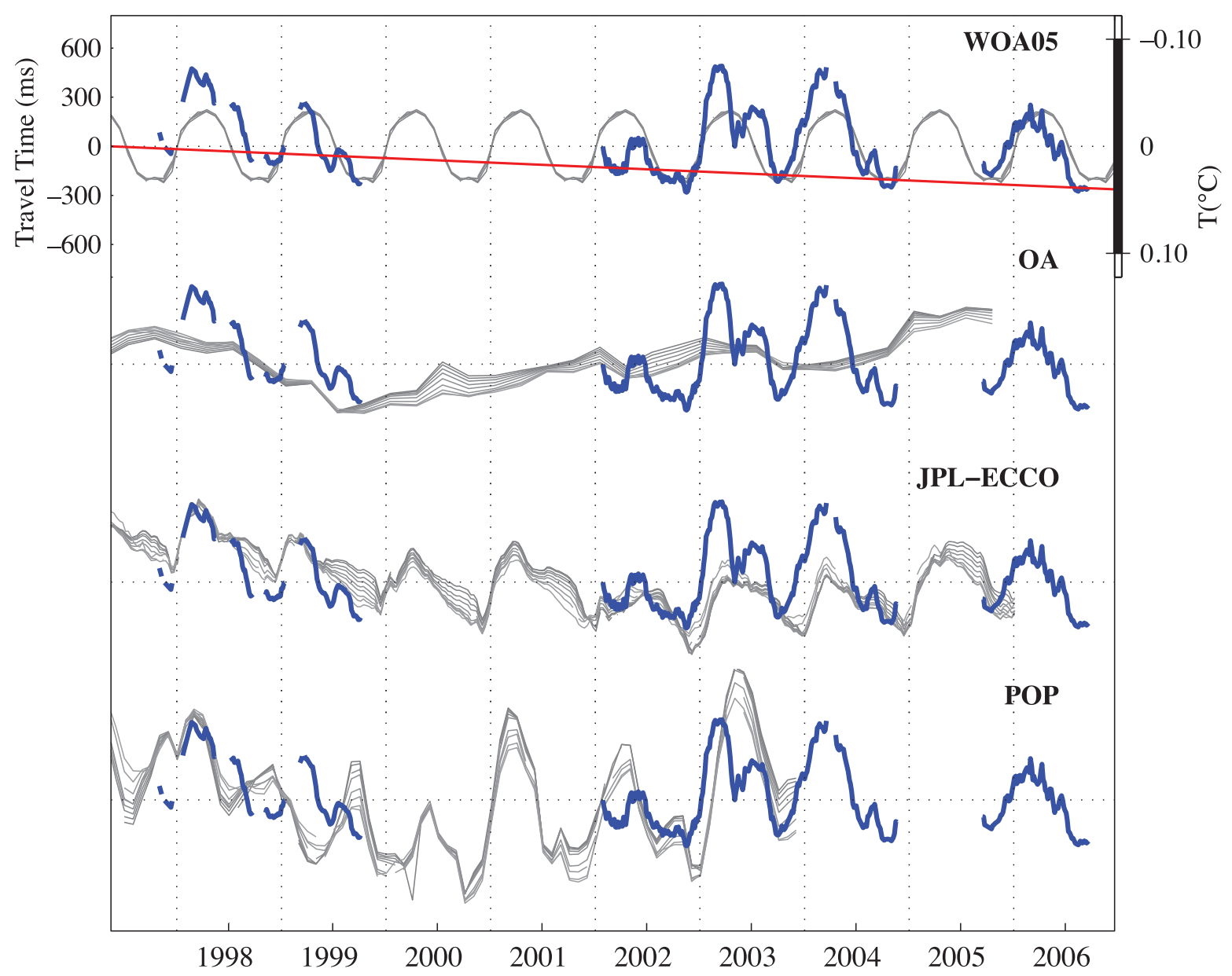

Figure 17. Comparison of measured travel times for transmissions from Kauai to $\mathrm{k}$ (blue) with travel times calculated using sound speed fields derived from WOA05, estimates of upper-ocean temperature profiles produced by an $\mathrm{OA}$ procedure that combines satellite altimetric height with in situ temperature profiles, the JPL-ECCO solutions, and the POP model (gray). The time means have been removed from all of the time series. Approximate estimates of temperature perturbations averaged along the raypath inferred from the travel times are shown on the right-hand axis. The nominal travel time trend corresponding to a warming of $5 \mathrm{~m}^{\circ} \mathrm{C} / \mathrm{a}$ on the sound channel axis, as suggested by Munk and Forbes [1989], is shown (red).

estimates proved incapable of reproducing the observed acoustic arrival patterns. No such difficulty was encountered when using the sound speed field derived from WOA05. Acoustic propagation calculations are sensitive to the vertical gradient of sound speed. Detailed examination of vertical profiles of the time mean from the JPL-ECCO and POP estimates showed that the vertical gradients are sufficiently unrealistic that acoustic calculations using the derived sound speed fields are also unrealistic. In order to proceed, it proved necessary to replace the time mean temperature and salinity fields in the JPL-ECCO and POP estimates with annual mean fields from WOA05, under the assumption that although the time mean states are unrealistic, the variability is still meaningful.

[59] In order to facilitate comparisons of the variability in the measured travel times with the variability in travel times calculated using sound speed fields derived from the various estimates of the temperature and salinity fields in the North
Pacific, Figure 17 and 18 bring together the results for the Kauai to $\mathrm{k}$ and Kauai to $\mathrm{f}$ paths for WOA05 (Figure 4), objective maps combining satellite altimetry and in situ temperature profiles (Figure 10), the JPL-ECCO solution (Figure 12), and the POP model (Figure 14). All of the travel time calculations shown in the preceding sections (and in Figures 17 and 18) were done for notional locations of receivers $(\mathrm{k}, 1, \mathrm{n}, \mathrm{o}, \mathrm{p})$, as given in Table 1 and shown in Figure 1. Redoing the calculations for the actual receiver locations results in minor changes in the predicted travel time variability. In some, but certainly not all, cases, the observed and predicted variability are in somewhat better agreement when the actual locations are used. Nonetheless, using the true locations does not change the conclusions given here.

[60] Perhaps the most striking feature of Figures 17 and 18 is the substantial variability in the measured travel times on interannual, seasonal, and shorter time scales. The interan- 


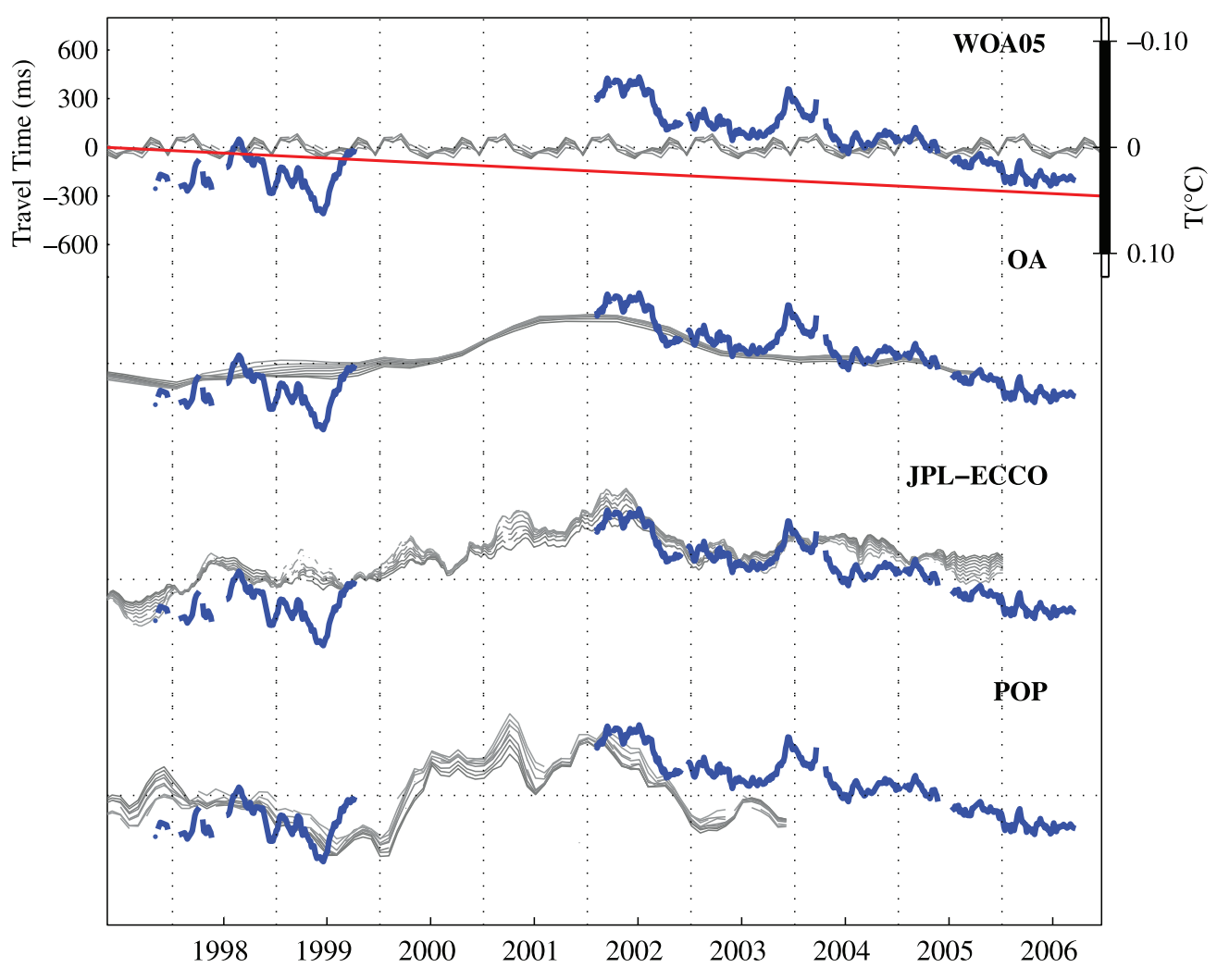

Figure 18. Same as Figure 17, except for transmissions from Kauai to f.

nual signal is large, more or less as expected [Mikolajewicz et al., 1993], with a seasonal cycle that is highly variable from year to year. Somewhat surprisingly, given the largescale spatial averaging provided by the acoustic measurements, large changes in travel time can occur rapidly, on time scales on the order of weeks. These rapid changes are sometimes related to the seasonal cycle, with cooling in the autumn or warming in spring. A dramatic example of rapid cooling for Kauai to $\mathrm{k}$ occurs during the winter of $2002-$ 2003. At other times, the rapid changes do not seem to be strongly related to the seasonal cycle. It is possible that some of these changes are related to the movements of ocean fronts [e.g., Spiesberger et al., 1983]. In the case of strong fronts, large travel time changes can occur when the frontal position shifts location and/or orientation relative to the acoustic path. Fronts are not well represented in the low-resolution fields provided by the objective maps and the JPL-ECCO solution, although strong, deep fronts are not expected in the northeast and north central Pacific in any event. The JPL-ECCO solution and the POP model reflect the observed variability with varying degrees of success. In 2003 for Kauai to k, for example, the JPLECCO solution predicts a smaller seasonal signal than measured, while the POP model predicts a larger signal. The annual-average travel times derived from satellite altimetry and in situ profiles of course show little of this temporal variability.

[61] On longer time scales, the measured travel times for the Kauai to f path show a warming trend (decreasing travel times) from 2002 to 2006 that is large compared to that estimated by Munk and Forbes [1989] and generally similar to that seen in the computed travel times for the objective maps and the JPL-ECCO solution (Figure 18). (The POP model estimates end in 2003.) The agreement is perhaps not surprising, as both the objective maps and JPL-ECCO solution use sea surface height and in situ profile data in generating ocean estimates. The agreement between the measured travel times and those computed for the JPLECCO solution is particularly striking during 2002-2003. The JPL-ECCO travel times show less warming than measured continuing into 2004-2005, however.

[62] Some of the discrepancies between the measured travel times and the computed travel times for the objective maps and the JPL-ECCO solution are likely related to instrumental problems in the in situ temperature profile data that were used. A number of Argo profiling floats deployed between mid-2003 and 2006 gave spuriously cold temperature profiles [Willis et al., 2007]. A timevarying warm bias is present in the global XBT data archive [Gouretski and Koltermann, 2007; Wijffels et al., 2008]. The Argo floats providing spuriously cold temperature profiles were deployed primarily in the Atlantic Ocean and therefore likely do not significantly affect the comparisons presented here. The biases in the XBT profiles will affect the comparisons, however. The measured acoustic travel times are not subject to similar calibration issues, as they depend only on the accurate measurement of time.

[63] The logical next step is to use acoustic travel times, together with other data, to constrain numerical ocean models. This approach allows rigorous comparison of the contributions that the various data types make to 
Table A1. RMS of the High-Frequency Residual Series, After Subtracting Daily Averages From the Travel Times for Each Resolved Ray Arrival

\begin{tabular}{lccc}
\hline Source & Receiver & Number of Rays & RMS (ms) \\
\hline Kauai & $\mathrm{k}$ & 6 & $25-30$ \\
Kauai & $\mathrm{n}$ & 6 & $22-28$ \\
Kauai & $\mathrm{r}$ & 6 & $19-31$ \\
Kauai & $\mathrm{f}$ & 9 & $26-34$ \\
Kauai & $\mathrm{o}$ & 8 & $17-26$ \\
Pioneer & $\mathrm{p}$ & 8 & $16-23$ \\
Pioneer & 1 & 6 & $18-36$ \\
Pioneer & $\mathrm{k}$ & 12 & $24-33$ \\
Pioneer & $\mathrm{n}$ & 6 & $14-23$ \\
Pioneer & $\mathrm{o}$ & 8 & $19-25$ \\
\hline
\end{tabular}

constraining model behavior. The acoustic data provide excellent signal-to-noise ratio measurements of large-scale temperature variability with high temporal resolution. The differences between the measured and computed acoustic travel times, which are comparable in size to the observed signals, indicate that the acoustic data can provide significant additional constraints for numerical ocean models, as suggested long ago by Munk and Wunsch [1982].

\section{Appendix A: Acoustic Instrumentation and Signal Processing}

[64] The acoustic instrumentation and signal processing are described in detail by the Howe et al. [1995]. Only a brief summary is given here.

[65] The acoustic sources were HX-554 bender-bar sources manufactured by Alliant Techsystems Inc. The sources transmitted phase-modulated signals in order to increase the signal-to-noise ratios at the receivers using pulse-compression techniques [e.g., Munk et al., 1995]. The phase modulation was encoded using binary linear maximallength sequences ( $m$ sequences) containing 1023 digits. Each digit consisted of two cycles of a $75-\mathrm{Hz}$ carrier, yielding a time resolution of $26.667 \mathrm{~ms}$, and each sequence period lasted $27.2800 \mathrm{~s}$. Transmissions normally contained 44 sequence periods (1200.320 s), of which 40 periods (1091.200 s) were recorded and processed. The source level was $195 \mathrm{~dB}$ re $1 \mu \mathrm{Pa}$ at $1 \mathrm{~m}(263 \mathrm{~W})$.

[66] The bottom-mounted horizontal receiving arrays are connected by undersea cables to shore, where data acquisition systems were installed to acquire and process the receptions. Beam forming of the signals from each array improved the signal-to-noise ratios and provided the conic angles of the arrivals relative to the array axis [Dushaw et al., 1999].

[67] The received signals were first processed to remove the phase modulation (i.e., pulse compression). Stable arrivals were then located by constructing a dot plot, in which every arrival peak exceeding a specified signal-tonoise ratio is located and its travel time plotted as a function of reception time and arrival angle. Ray arrivals are evident in this plot from their continuity from reception to reception, while noise peaks are random. The next step was to identify the ray arrivals evident in the dot plots with specific raypaths by comparison to arrival patterns predicted by ray trace programs using historical hydrographic data, e.g., WOA05. Time series of acoustic travel times were then generated by tracking the identified paths from one reception to the next. Precision timing at the sources and the cabled receivers was provided by Global Positioning System receivers. Finally, the time series were low-pass filtered by averaging over a day to generate daily-average travel times for each resolved ray arrival.

[68] The residual high-frequency travel times include the effects of internal waves [Flatté et al., 1979], as well as barotropic and baroclinic tides [Dushaw et al., 1995]. Travel time signals due to barotropic tidal currents evident in the high-frequency travel times for some acoustic paths have been found to be consistent with tidal models [Dushaw et al., 1999]. The RMS of the high-frequency residual series provides a direct estimate of the travel time precision for the resolved ray arrivals (Table A1).

[69] Dushaw et al. [1999] describe the receptions on the bottom-mounted hydrophone arrays for transmissions from the Pioneer Seamount source in some detail.

\section{Appendix B: Merging Upper-Ocean Temperature Profiles With the Abyssal World Ocean Atlas}

[70] In order to construct the full-ocean-depth sound speed fields needed to compute acoustic travel times, the upper-ocean temperature profiles $(0$ to $750 \mathrm{~m})$ produced by combining satellite altimetric height with in situ temperature profiles [Willis et al., 2003, 2004, 2007; Lyman et al., 2006] need to be extended into the abyssal ocean, and appropriate salinity profiles need to be generated (Figure B1).

[71] Salinities are first assigned to the $0-$ to $750-\mathrm{m}$ temperature profiles using annual mean temperature-salinity $(T-S a)$ relations at each grid point derived from WOA05. Salinity values are calculated by linearly interpolating the $T-S a$ relations. Although the values of salinity assigned in this way contain errors, sound speed is only a weak function of salinity. A relatively large salinity error of 1 psu translates into a sound speed error of only about $1.3 \mathrm{~m} / \mathrm{s}$, for example, and the effect on the computed travel times is therefore small.

[72] The 0 - to $750-\mathrm{m}$ profiles of temperature and salinity are subsequently merged with WOA05 annual mean temperature and salinity profiles extending from $750 \mathrm{~m}$ to the full ocean depth. Ray calculations are sensitive to sound speed gradients, and it is therefore important to maintain smooth transitions between the 0 - to $750-\mathrm{m}$ profiles and the climatological data. A smoothing cubic spline technique that allows for data misfit is used for this purpose. Small uncertainties are assigned to the 0 - to $750-\mathrm{m}$ profiles, and large uncertainties (five times greater) are assigned to the annual mean profiles at depths below $750 \mathrm{~m}$. The cubic spline fit therefore gives profiles that closely follow the upper-ocean values, while making a smooth transition to the climatological values in the abyssal ocean.

[73] Once temperature and salinity profiles are constructed, pressure is calculated using standard routines [Fofonoff and Millard, 1983]. Sound speed is then calculated using the Del Grosso sound speed equation [Del Grosso, 1974]. Finally, sound speed sections are determined 

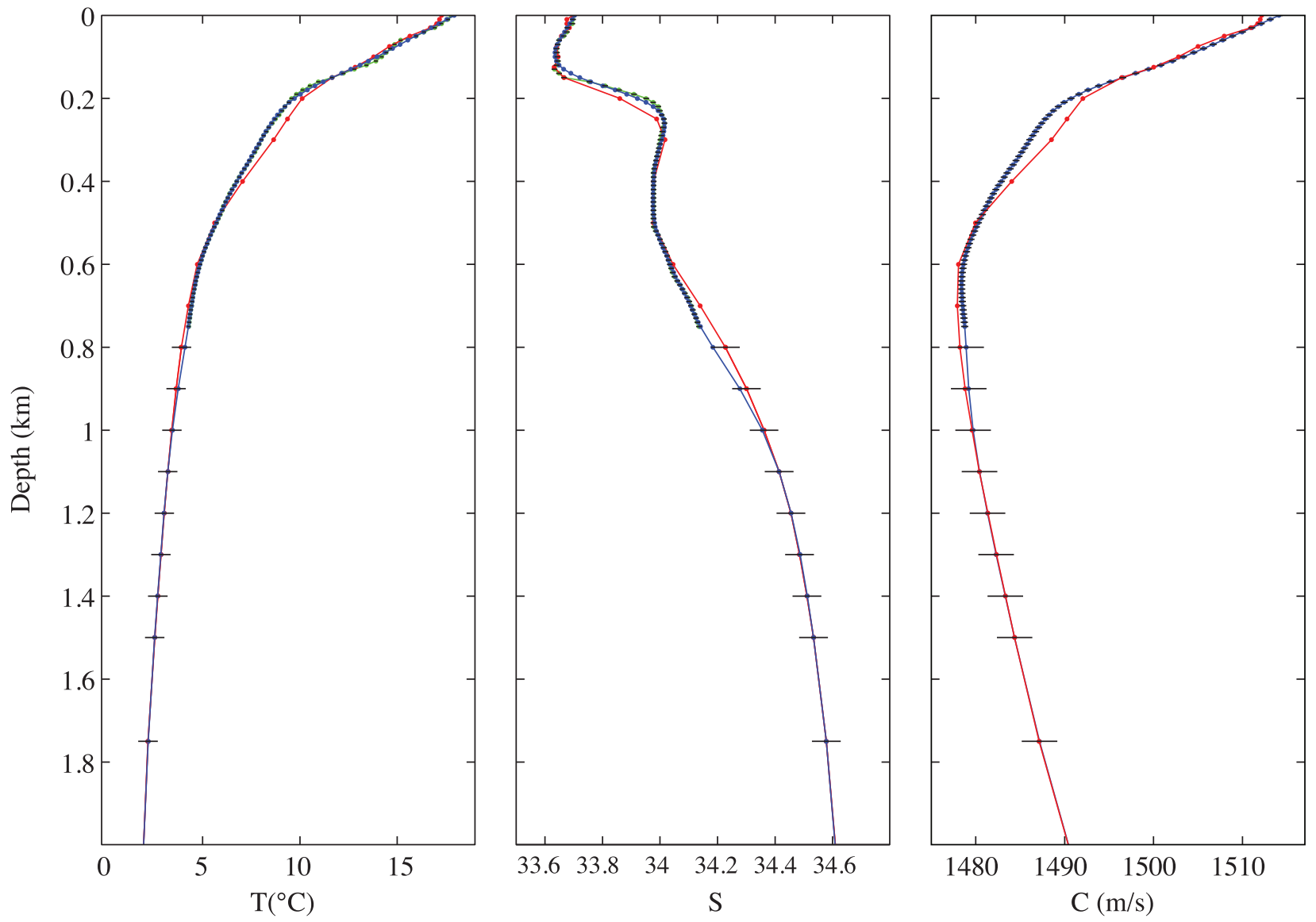

Figure B1. (left) Upper-ocean temperature profiles at $36.8^{\circ} \mathrm{N}, 140.0^{\circ} \mathrm{W}$ from the objective maps (green) are combined with annual mean temperature profiles from WOA05 (red) using smoothed cubic splines to give merged profiles (blue). (middle) Annual average $T-S a$ relations derived from WOA05 are used to generate salinity profiles in the upper $750 \mathrm{~m}$ (green) from the temperature profiles. The upper-ocean salinity profiles are combined with annual average salinity profiles from WOA05 using smoothed cubic splines to give merged profiles (blue). (right) The merged profiles of temperature and salinity are used to calculate the sound speed profiles (blue) used for the acoustic calculations. The sound speed profile derived from WOA05 is shown in red for comparison.

along the acoustic paths by two-dimensional linear interpolation at each depth.

[74] Acknowledgments. Our colleagues in the ATOC Consortium (A. B. Baggeroer, T. G. Birdsall, C. Clark, J. A. Colosi, B. D. Cornuelle, D. Costa, B. D. Dushaw, M. A. Dzieciuch, A. M. G. Forbes, C. Hill, B. M. Howe, J. Marshall, D. Menemenlis, J. A. Mercer, K. Metzger, W. H Munk, R. C. Spindel, D. Stammer, P. F. Worcester, and C. Wunsch) and the NPAL Group (J. A. Colosi, B. D. Cornuelle, B. D. Dushaw, M. A. Dzieciuch, B. M. Howe, J. A. Mercer, W. H. Munk, R. C. Spindel, and P. F. Worcester) all contributed in various ways to obtaining the data presented here. L. Olson, J. Watson, F. Karig, D. Reddaway, S. Leach, S. Weslander, and L. Buck, at the Applied Physics Laboratory, University of Washington, contributed significantly to the installation of the acoustic sources and the data acquisition systems for the bottom-mounted receivers and to the associated data collection. ATOC was supported by Defense Advanced Research Projects Agency (DARPA) grant MDA972-93-1-0003, with funds provided by the Strategic Environmental Research and Development Program (SERDP). NPAL was supported by the Office of Naval Research.

\section{References}

Advanced Research Projects Agency and National Marine Fisheries Service (1995), Final environmental impact statement for the Kauai Acoustic Thermometry of Ocean Climate Project and its associated Marine Mammal Research Program, report, Adv. Res. Proj. Agency and Natl. Mar. Fish. Serv., Silver Spring, Md.
Advanced Research Projects Agency, National Marine Fisheries Service, and University of California, San Diego (1995), Final environmental impact statement/environmental impact report for the California Acoustic Thermometry of Ocean Climate Project and its associated Marine Mammal Research Program, report, Adv. Res. Proj. Agency, Natl. Mar. Fish. Serv., and Univ. of Calif., San Diego, La Jolla.

Antonov, J. I., R. A. Locarnini, T. P. Boyer, A. V. Mishonov, and H. E. Garcia (2006), World Ocean Atlas 2005, vol. 2, Salinity, NOAA Atlas NESDIS 62, 182 pp., Natl. Oceanic and Atmos. Admin., Washington, D. C.

Baggeroer, A. B., et al. (1998), Ocean climate change: Comparison of acoustic tomography, satellite altimetry, and modeling, Science, 281, $1327-1332$

Bond, N. A., J. E. Overland, M. Spillane, and P. Stabeno (2003), Recent shifts in the state of the North Pacific, Geophys. Res. Lett., 30(23), 2183, doi:10.1029/2003GL018597.

Brekhovskikh, L. M., and Y. P. Lysanov (2003), Fundamentals of Ocean Acoustics, 3rd ed., 278 pp., Springer, Berlin.

Carton, J. A., and A. Santorelli (2008), Global decadal upper ocean heat content as viewed in nine analyses, J. Clim., 21, 6015-6035.

Chiu, C.-S., A. J. Semtner, C. M. Ort, J. H. Miller, and L. L. Ehret (1994), A ray variability analysis of sound transmission from Heard Island to California, J. Acoust. Soc. Am., 96, 2380-2388.

Cornuelle, B. D., and P. F. Worcester (1996), Ocean acoustic tomography: Integral data and ocean models, in Modern Approaches to Data Assimilation in Ocean Modeling, edited by P. Malanotte-Rizzoli, pp. 97-115, Elsevier Sci., Amsterdam. 
Del Grosso, V. A. (1974), New equation for the speed of sound in natural waters (with comparisons to other equations), J. Acoust. Soc. Am., 56 1084-1091.

Domingues, C. M., J. A. Church, N. J. White, P. J. Gleckler, S. E. Wijffels, P. M. Barker, and J. R. Dunn (2008), Improved estimates of upper-ocean warming and multi-decadal sea-level rise, Nature, 453, 1090-1093.

Dukowicz, J. K., and R. D. Smith (1994), Implicit free-surface method for the Bryan-Cox-Semtner ocean model, J. Geophys. Res., 99, 7991-8014.

Dukowicz, J. K., R. D. Smith, and R. C. Malone (1993), A reformulation and implementation of the Bryan-Cox-Semtner ocean model on the Connection Machine, J. Atmos. Oceanic Technol., 10, 195-208.

Dushaw, B. D. (1999), Inversion of multimegameter-range acoustic data for ocean temperature, IEEE J. Ocean. Eng., 24, 215-223.

Dushaw, B. D., P. F. Worcester, B. D. Cornuelle, and B. M. Howe (1993a), On equations for the speed of sound in seawater, J. Acoust. Soc. Am., 93, $255-275$.

Dushaw, B. D., P. F. Worcester, B. D. Cornuelle, and B. M. Howe (1993b), Variability of heat content in the central North-Pacific in summer 1987 determined from long-range acoustic transmissions, J. Phys. Oceanogr., $23,2650-2666$

Dushaw, B. D., B. D. Cornuelle, P. F. Worcester, B. M. Howe, and D. S. Luther (1995), Barotropic and baroclinic tides in the central North Pacific Ocean determined from long-range reciprocal acoustic transmissions, $J$. Phys. Oceanogr., 25, 631-647.

Dushaw, B. D., et al. (1999), Multimegameter-range acoustic data obtained by bottom-mounted hydrophone arrays for measurement of ocean temperature, IEEE J. Ocean. Eng., 24, 202-214.

Dushaw, B. D., et al. (2001), Observing the ocean in the 2000's: A strategy for the role of acoustic tomography in ocean climate observation, in Observing the Oceans in the 21st Century, edited by C. J. Koblinsky and N. R. Smith, pp. 391-418, GODAE Proj. Off. and Bur. of Meteorol., Melbourne, Vic., Australia.

Flatté, S. M., R. Dashen, W. H. Munk, K. M. Watson, and F. Zachariasen (1979), Sound Transmission Through a Fluctuating Ocean, 299 pp. Cambridge Univ. Press, Cambridge, U. K.

Fofonoff, N. P., and R. C. Millard Jr. (1983), Algorithms for computation of fundamental properties of seawater, UNESCO Tech. Pap. Mar. Sci., 44, 53 pp.

Fukumori, I. (2002), A partitioned Kalman filter and smoother, Mon. Weather Rev., 130, 1370-1383.

Gavrilov, A. N., and P. N. Mikhalevsky (2006), Low-frequency acoustic propagation loss in the Arctic Ocean: Results of the Arctic climate observations using underwater sound experiment, J. Acoust. Soc. Am., 119, 3694-3706.

Gouretski, V., and K. P. Koltermann (2007), How much is the ocean really warming?, Geophys. Res. Lett., 34, L01610, doi:10.1029/ 2006GL027834.

Heaney, K. D. (2005), The Kauai Near-Source Test (KNST): Modeling and measurements of downslope propagation near the North Pacific Acoustic Laboratory (NPAL) Kauai source, J. Acoust. Soc. Am., 117, 1635-1642.

Howe, B. M., et al. (1995), Instrumentation for the Acoustic Thermometry of Ocean Climate (ATOC) prototype Pacific Ocean network, in OCEANS '95 MTS/IEEE Conference Proceedings, pp. 1483-1500, Mar. Technol. Soc., Columbia, Md.

Howe, B. M., et al. (2004), Acoustic remote sensing of large-scale temperature variability in the North Pacific Ocean, in OCEANS'04, MTS/IEEE Techno-Ocean '04, pp. 1504-1506, Mar. Technol. Soc., Columbia, Md.

Kalnay, E., et al. (1996), The NCEP/NCAR 40-year reanalysis project, Bull. Am. Meteorol. Soc., 77, 437-471.

Levitus, S., J. I. Antonov, and T. P. Boyer (2005), Warming of the world ocean, 1955-2003, Geophys. Res. Lett., 32, L02604, doi:10.1029/ 2004GL021592.

Locarnini, R. A., A. V. Mishonov, J. I. Antonov, T. P. Boyer, and H. E. Garcia (2006), World Ocean Atlas 2005, vol. 1, Temperature, NOAA Atlas NESDIS 61, 182 pp., Natl. Oceanic and Atmos. Admin., Washington, D. C.

Lukas, R. (2001), Freshening of the upper thermocline in the North Pacific subtropical gyre associated with decadal changes of rainfall, Geophys. Res. Lett., 28, 3485-3488, doi:10.1029/2001GL013116.

Lyman, J. M., J. K. Willis, and G. C. Johnson (2006), Recent cooling of the upper ocean, Geophys. Res. Lett., 33, L18604, doi:10.1029/ 2006GL027033.

Maltrud, M. E., and J. L. McClean (2005), An eddy resolving global 1/10 ocean simulation, Ocean Modell., 8, 31-54.

Mantua, N. J., S. R. Hare, Y. Zhang, J. M. Wallace, and R. C. Francis (1997), A Pacific interdecadal climate oscillation with impacts on salmon production, Bull. Am. Meteorol. Soc., 78, 1069-1079.

Marshall, J., A. Adcroft, C. Hill, L. Perelman, and C. Heisey (1997), A finite-volume, incompressible Navier Stokes model for studies of the ocean on parallel computers, J. Geophys. Res., 102, 5753-5766.
McClean, J. L., M. E. Maltrud, and F. O. Bryan (2006), Measures of the fidelity of eddying ocean models, Oceanography, 19, 104-117.

McDonald, B. E., M. D. Collins, W. A. Kuperman, and K. D. Heaney (1994), Comparison of data and model predictions for Heard Island acoustic transmissions, J. Acoust. Soc. Am., 96, 2357-2370.

Menemenlis, D., T. Webb, C. Wunsch, U. Send, and C. Hill (1997), Basinscale ocean circulation from combined altimetric, tomographic and model data, Nature, 385, 618-621.

Menemenlis, D., I. Fukumori, and T. Lee (2005), Using Green's functions to calibrate an ocean general circulation model, Mon. Weather Rev., 133, $1224-1240$

Mikhalevsky, P. N., and A. N. Gavrilov (2001), Acoustic thermometry in the Arctic Ocean, Pol. Res., 20, 185-192, doi:10.1111/j.1751-8369. 2001.tb00055.x

Mikhalevsky, P. N., A. N. Gavrilov, and A. B. Baggeroer (1999), The Transarctic Acoustic Propagation Experiment and climate monitoring in the Arctic, IEEE J. Ocean. Eng., 24, 183-201.

Mikolajewicz, U., E. Maier-Reimer, and T. P. Barnett (1993), Acoustic detection of greenhouse-induced climate changes in the presence of slow fluctuations of the thermohaline circulation, J. Phys. Oceanogr., 23, 1099-1109.

Miller, A. J., and N. Schneider (2000), Interdecadal climate regime dynamics in the North Pacific Ocean: Theories, observations and ecosystem impacts, Prog. Oceanogr., 47, 355-379.

Moisan, J. R., and P. P. Niiler (1998), The seasonal heat budget of the North Pacific: Net heat flux and heat storage rates $(1950-1990)$, J. Phys. Oceanogr., 28, 401-421.

Munk, W. H. (2006), Ocean acoustic tomography: From a stormy start to an uncertain future, in Physical Oceanography: Developments Since 1950, edited by M. Jochum and R. Murtugudde, pp. 119-138, Springer, New York.

Munk, W. H., and A. M. G. Forbes (1989), Global ocean warming: An acoustic measure?, J. Phys. Oceanogr., 19, 1765-1778.

Munk, W. H., and C. Wunsch (1982), Observing the ocean in the 1990's, Philos. Trans. R. Soc. London, Ser. A, 307, 439-464.

Munk, W. H., R. C. Spindel, A. Baggeroer, and T. G. Birdsall (1994), The Heard Island Feasibility Test, J. Acoust. Soc. Am., 96 , $2330-2342$.

Munk, W. H., P. F. Worcester, and C. Wunsch (1995), Ocean Acoustic Tomography, 433 pp., Cambridge University Press, Cambridge, U. K.

Norris, D. E., J. L. Spiesberger, and D. W. Merdes (1998), Comparison of basin-scale acoustic transmissions with rays and further evidence for a structured thermal field in the northeast Pacific, J. Acoust. Soc. Am., 103 $182-194$

Ocean Tomography Group (1982), A demonstration of ocean acoustic tomography, Nature, 299, 121-125.

Office of Naval Research (2001), Final environmental impact statement for the North Pacific Acoustic Laboratory, report, Off. of Nav. Res., Arlington, $\mathrm{Va}$

Semtner, A. J., Jr., and R. M. Chervin (1990), Environmental effects on acoustic measures of global ocean warming, J. Geophys. Res., 95, $12,973-12,982$

Send, U., G. Krahmann, D. Mauuary, Y. Desaubies, F. Gaillard, T. Terre, J. Papadakis, M. Taroudakis, E. Skarsoulis, and C. Millot (1997), Acoustic observations of heat content across the Mediterranean Sea, Nature, 385, 615-617.

Skarsoulis, E. K., U. Send, G. Piperakis, and P. Testor (2004), Acoustic thermometry of the western Mediterranean basin, J. Acoust. Soc. Am. 116, 790-798.

Smith, R. D., J. K. Dukowicz, and R. C. Malone (1992), Parallel ocean general circulation modeling, Physica D, 60, 38-61.

Spiesberger, J. L., and K. Metzger (1991), Basin-scale tomography: A new tool for studying weather and climate, J. Geophys. Res., 96, $4869-4889$

Spiesberger, J. L., and F. D. Tappert (1996), Kaneohe acoustic thermometer further validated with rays over $3700 \mathrm{~km}$ and the demise of the idea of axially trapped energy, J. Acoust. Soc. Am., 99, 173-184.

Spiesberger, J. L., T. G. Birdsall, K. Metzger, R. A. Knox, C. W. Spofford, and R. C. Spindel (1983), Measurements of Gulf Stream meandering and evidence of seasonal thermocline development using long-range acoustic transmissions, J. Phys. Oceanogr., 13, 1836-1846.

Spiesberger, J. L., P. J. Bushong, K. Metzger, and T. G. Birdsall (1989), Basin-scale tomography: Synoptic measurements of a 4000-km length section in the Pacific, J. Phys. Oceanogr., 19, 1073-1090.

Spiesberger, J. L., K. Metzger, and J. A. Furgerson (1992), Listening for climatic temperature change in the northeast Pacific: 1983-1989, J. Acoust. Soc. Am., 92, 384-396.

Spiesberger, J. L., E. Terray, and K. Prada (1994), Successful ray modeling of acoustic multipaths over a $3000-\mathrm{km}$ section in the Pacific, J. Acoust. Soc. Am., 95, 3654-3657. 
Spiesberger, J. L., H. E. Hurlburt, M. Johnson, M. Keller, S. Meyers, and J. O'Brien (1998), Acoustic thermometry data compared with two ocean models: The importance of Rossby waves and ENSO in modifying the ocean interior, Dyn. Atmos. Oceans, 26, 209-240.

Staten, R. A., C.-S. Chiu, and A. J. Semtner Jr. (1996), A simulation study of the variability of acoustic transmissions from Hawaii to Monterey, in Theoretical and Computational Acoustics '95, edited by D. Lee et al., pp. 505-525, World Sci., Singapore.

Van Uffelen, L. J., P. F. Worcester, M. A. Dzieciuch, and D. L. Rudnick (2009), The vertical structure of shadow-zone arrivals at long range in the ocean, J. Acoust. Soc. Am., 125(6), 3569-3588, doi:10.1121/1.3117430.

Vera, M. D., et al. (2005), The effect of bottom interaction on transmissions from the North Pacific Acoustic Laboratory Kauai source, J. Acoust. Soc. Am., 117, 1624-1634

Wijffels, S. E., J. Willis, C. M. Domingues, P. Barker, N. J. White, A. Gronell, K. Ridgway, and J. A. Church (2008), Changing expendable bathythermograph fall rates and their impact on estimates of thermosteric sea level rise, J. Clim., 21, 5657-5672.

Willis, J. K., D. Roemmich, and B. D. Cornuelle (2003), Combining altimetric height with broadscale profile data to estimate steric height, heat storage, subsurface temperature, and sea-surface temperature variability, J. Geophys. Res., 108(C9), 3292, doi:10.1029/2002JC001755.

Willis, J. K., D. Roemmich, and B. D. Cornuelle (2004), Interannual variability in upper ocean heat content, temperature, and thermosteric expansion on global scales, J. Geophys. Res., 109, C12036, doi:10.1029/ 2003JC002260.

Willis, J. K., J. M. Lyman, G. C. Johnson, and J. Gilson (2007), Correction to "Recent cooling of the upper ocean," Geophys. Res. Lett., 34, L16601, doi:10.1029/2007GL030323.

Worcester, P. F. (2001), Tomography, in Encyclopedia of Ocean Sciences, edited by J. Steele et al., pp. 2969-2986, Academic, London.
Worcester, P. F., and R. C. Spindel (2005), North Pacific Acoustic Laboratory, J. Acoust. Soc. Am., 117, 1499-1510.

Worcester, P. F., B. D. Cornuelle, J. A. Hildebrand, W. S. Hodgkiss, T. F. Duda, J. Boyd, B. M. Howe, J. A. Mercer, and R. C. Spindel (1994), A comparison of measured and predicted broadband acoustic arrival patterns in travel time-depth coordinates at 1000-km range, J. Acoust. Soc. Am., 95, 3118-3128.

Worcester, P. F., et al. (1999), A test of basin-scale acoustic thermometry using a large-aperture vertical array at $3250-\mathrm{km}$ range in the eastern North Pacific Ocean, J. Acoust. Soc. Am., 105, 3185-3201.

Worcester, P. F., W. H. Munk, and R. C. Spindel (2005), Acoustic remote sensing of ocean gyres, Acoust. Today, 1, 11-17.

Wunsch, C., and P. Heimbach (2006), Practical global oceanic state estimation, Physica D, 230, 197-208.

R. K. Andrew, B. D. Dushaw, B. M. Howe, J. A. Mercer, and R. C. Spindel, Applied Physics Laboratory, University of Washington, 1013 Northeast 40th Street, Seattle, WA 98105, USA. (dushaw@apl.washington. edu)

T. G. Birdsall and K. Metzger Jr., Department of Electrical Engineering and Computer Science, University of Michigan, Ann Arbor, MI 481092122, USA.

B. D. Cornuelle, M. A. Dzieciuch, W. H. Munk, and P. F. Worcester, Scripps Institution of Oceanography, University of California at San Diego, La Jolla, CA 92093-0225, USA.

D. Menemenlis, Jet Propulsion Laboratory, California Institute of Technology, 4800 Oak Grove Drive, Pasadena, CA 91109, USA. 